\title{
SIMULATION OF ENZYMATIC PRODUCTION OF AMOXICILLIN \\ By
}

\author{
ZAFAR UDDIN KHAN \\ (M.Sc University of Karachi, Pakistan 1994) \\ (M.Phil University of Karachi, Pakistan 2000)
}

\author{
A project report \\ presented to Ryerson University \\ in partial fulfillment of the \\ requirement for the degree of \\ Master of Engineering \\ in the program of \\ Chemical Engineering
}

Toronto, Ontario, Canada, 2004

(C) Zafar Uddin Khan 2004 
UMI Number: EC53412

\section{INFORMATION TO USERS}

The quality of this reproduction is dependent upon the quality of the copy submitted. Broken or indistinct print, colored or poor quality illustrations and photographs, print bleed-through, substandard margins, and improper alignment can adversely affect reproduction.

In the unlikely event that the author did not send a complete manuscript and there are missing pages, these will be noted. Also, if unauthorized copyright material had to be removed, a note will indicate the deletion.

\section{UMI}

UMI Microform EC53412

Copyright 2009 by ProQuest LLC

All rights reserved. This microform edition is protected against unauthorized copying under Title 17, United States Code.

ProQuest LLC

789 East Eisenhower Parkway

P.O. Box 1346

Ann Arbor, MI 48106-1346 


\section{AUTHOR'S DECLARATION}

I hereby declare that I am the sole author of this project report.

I authorize Ryerson University to lend this report to other institutions or individuals for the purpose of scholarly research.

Zafar Uddin Khan

I further authorize Ryerson University to reproduce this report by photocopying or by other means, in total or parts, at the request of other institutions or individuals for the purpose of scholarly research.

Zafar Uddin Khan 


\section{BORROWER'S PAGE}

Ryerson University requires the signatures of all persons using or photocopying this project report. Please sign below, and give address and date.

\begin{tabular}{|l|l|l|l|l|}
\hline No & Borrower's Name & Address & Date & Signature \\
\hline 1 & & & & \\
\hline 2 & & & & \\
\hline 3 & & & & \\
\hline 4 & & & & \\
\hline 5 & & & & \\
\hline 6 & & & & \\
\hline 7 & & & & \\
\hline 8 & & & & \\
\hline 9 & & & & \\
\hline 10 & & & & \\
\hline 11 & & & & \\
\hline 12 & & & & \\
\hline 13 & & & & \\
\hline 14 & & & & \\
\hline 15 & & & & \\
\hline 16 & & & & \\
\hline 17 & & & & \\
\hline 18 & & & & \\
\hline 19 & & & & \\
\hline 20 & & & & \\
\hline 21 & & & & \\
\hline 22 & & & & \\
\hline 23 & & & & \\
\hline 24 & & & & \\
\hline 25 & & & & \\
\hline
\end{tabular}




\section{ABSTRACT}

This project report is an attempt to find better conditions and reaction parameters for the potential commercialization of the enzymatic production of amoxicillin. A kinetic model from the literature was used to describe a reaction between $p$-hydroxyphenylglycine methyl ester (PHPGME) and 6-aminopenicillanic acid (6-APA) that is catalyzed by penicillin G acylase immobilized onto glyoxyl-agarose gel beads. A $\mathrm{C}++$ computer program was developed using a Fourth Order Runge-Kutta method to simulate higher substrate and enzyme concentration during the reaction. For model validation, simulation results were compared with experimental data from the literature and fractional errors. This simulation model predicted $24 \%$ yield of amoxicillin at high substrate concentration $(50 \mathrm{mM}$ of 6-APA; $300 \mathrm{mM}$ of PHPGME). It also predicted that increasing the enzyme concentration by four fold could produce a similar amoxicillin yield four times faster. The simulation results obtained in this work could be used in the future to aid in optimization and in further modifications of the kinetic model to predict even better yields. This enzymatic process could therefore become an industrial process to substitute the existing chemical route, which contains toxic organic solvents. 


\section{ACKNOWLEDGEMENTS}

I would like to express my sincere appreciation and gratitude to Dr. Ginette Turcotte, my advisor, for her unfailing support and guidance during the production of this report. Her valuable remarks were greatly useful and helpful to achieve effective and beneficial results.

I would also like to record my debt to all faculty and staff members of the Department of Chemical Engineering for their cooperation during my stay in the program.

I deeply thank my colleagues and friends Adnan Khan, Hafiz Abdullah, Yoshiki Kitano, Terry Roberts, Arif Kazmi and Nasir Naqvi who have been great sounding boards and leaning posts over the past two years.

I am especially indebted to my wife Asia Khan and my little kids Shaheer, Asfa and Hareem for their patience and true understanding of my neglect of them during the busy period. Without their support, love and encouragement, the completion of this work would not have been possible to me. 


\section{DEDICATED TO MY PARENTS}

Who always stand by me and provide me both moral and material support that I can never repay. 


\section{TABLE OF CONTENTS}

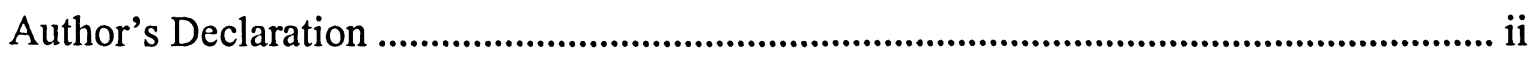

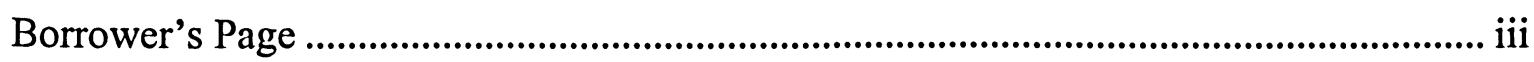

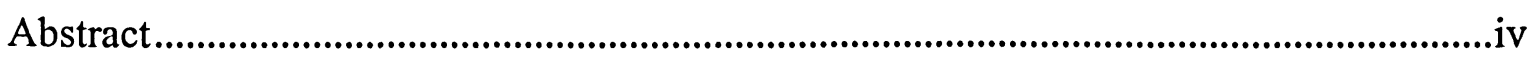

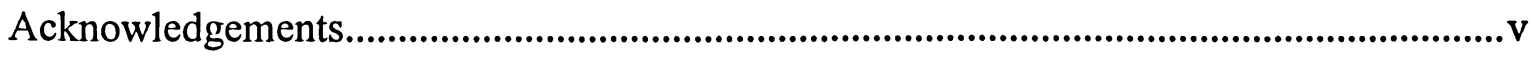

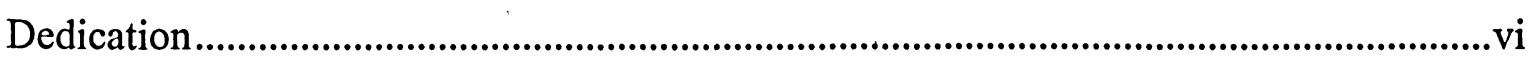

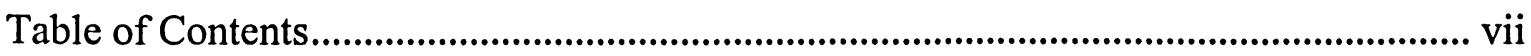

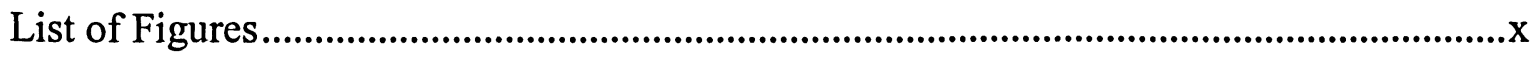

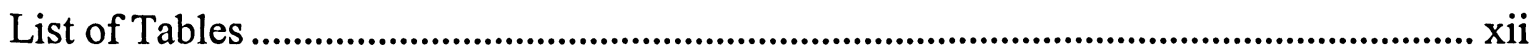

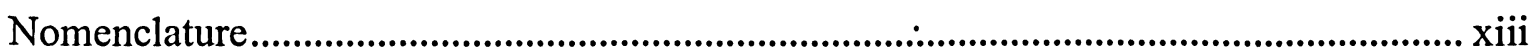

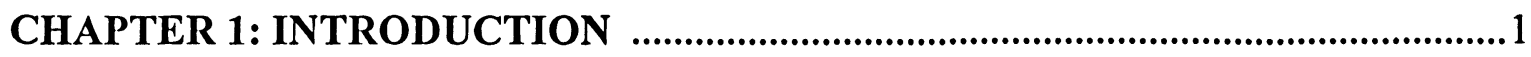

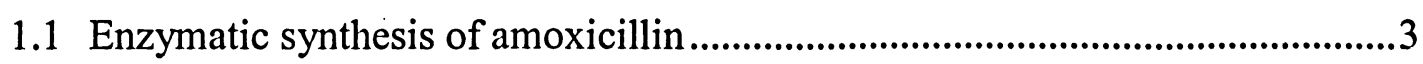

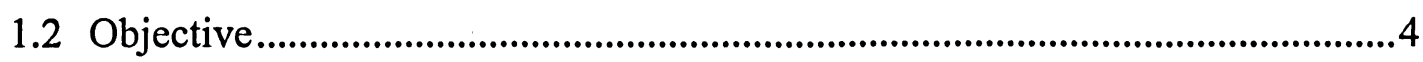

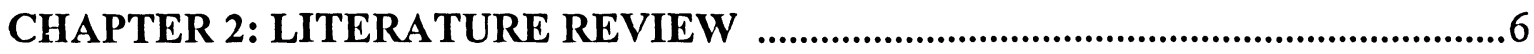

2.1 Thermodynamically controlled synthesis .........................................................6

2.2 Kinetically controlled synthesis.......................................................................

CHAPTER 3: KINETICS OF ENZYME-CATALYZED REACTIONS ..................11

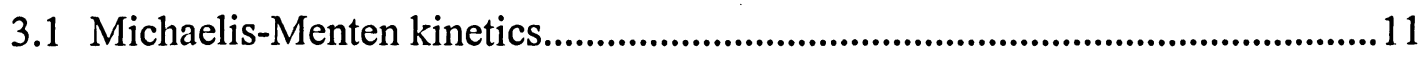

3.2 Enzyme activity and enzyme concentration ....................................................13 
4.1 Assumptions for the kinetic model .............................................................15

4.2 Model equations....................................................................................................15

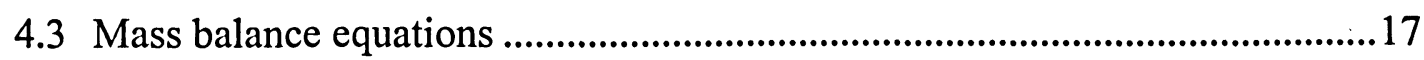

4.4 Model parameters ............................................................................................... 18

4.5 Fourth Order Runge-Kutta method .................................................................. 18

4.6 Validation of the simulation .............................................................................. 19

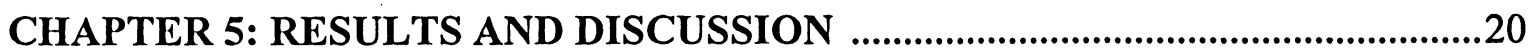

5.1 Comparison of simulation results with experimental data ................................20

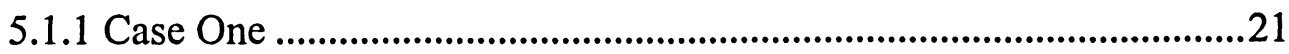

5.1.2 Case Two

5.1.3 Case Three.............................................................................................24

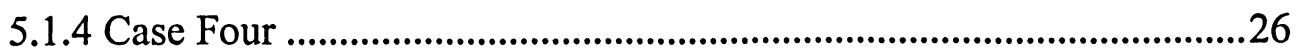

5.2 Prediction of the effect of high substrate concentration ....................................28

5.3 Prediction of the effect of high enzyme concentration.......................................30

CHAPTER 6: CONCLUSION AND FUTURE WORK …............................................32

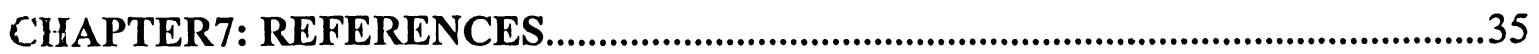




\section{APPENDICES}

Appendix A: Fourth Order algorithm for Runge-Kutta method.............................................39

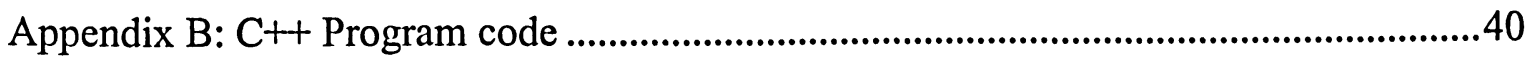

Appendix C: Experimental data from literature .............................................................49 


\section{LIST OF FIGURES}

Figure Description

Page

1.1 Enzymatic synthesis of amoxicillin with side reactions (Goncalves et al., 2000). 4

5.1 Comparison of simulation results with experimental data (Goncalves et al., 2002) 21 at initial concentrations of $100 \mathrm{mM}$ 6-APA and 70mM PHPGME.

5.2 Fractional error in simulating experimental amoxicillin concentration 22 (Goncalves et al., 2002) by the Fourth Order Runga-Kutta (•) compared to the literature simulation (O) for 100mM 6-APA and 70mM PHPGME (Case One).

5.3 Comparison of simulation results with experimental data (Goncalves et al., 2002) 23 at initial concentrations of 50mM 6-APA and 50mM PHPGME.

5.4 Fractional error in simulating experimental amoxicillin concentration 24 (Goncalves et al., 2002) by the Fourth Order Runga-Kutta (•) compared to the literature simulation (o) for 50mM 6-APA and 50mM PHPGME (Case Two).

5.5 Comparison of simulation results with experimental data (Goncalves et al., 2002) 25 at initial concentrations of 5mM 6-APA and 80mM PHPGME.

5.6 Fractional error in simulating experimental amoxicillin concentration 26 (Goncalves et al., 2002) by the Fourth Order Runga-Kutta (•) compared to the literature simulation (०) for 5mM 6-APA and 80mM PHPGME (Case Three).

5.7 Comparison of simulation results with experimental data (Goncalves et al., 2002) 27 at initial concentrations of 5mM 6-APA and 5mM PHPGME.

5.8 Predicted amoxicillin concentration at 50mM 6-APA and $100-300 \mathrm{mM}$ PHPGME. 
5.9 Predicted amoxicillin concentration at $200 \mathrm{mM} 6-\mathrm{APA}$ and $200-600 \mathrm{mM}$ PHPGME.

5.10 Predicted amoxicillin concentration with increased enzyme concentration at 50mM 6-APA. Other conditions similar to those of Figure 5.8.

5.11 Predicted amoxicillin concentration with increased enzyme concentration at 200mM 6-APA. Other conditions similar to those of Figure 5.9.

6.1 Ampicillin production at $\mathrm{pH} 6$ and pH 7 (Ospina et al., 1996). 


\section{LIST OF TABLES}

Table

4.1 Value of model parameters at $\mathrm{pH} 6.5$ and $25^{\circ} \mathrm{C}$. 18

C.1 Experimental data for the enzymatic synthesis of amoxicillin at $\mathrm{pH} 6.5$

and $25^{\circ} \mathrm{C}$ with $100 \mathrm{mM}$ of $6-\mathrm{APA}$ reacting with $70 \mathrm{mM}$ of PHPGME in the presence of $1 \mathrm{~g}$ of $30 \mathrm{IU} / \mathrm{ml}$ PGA.

C.2 Experimental data for the enzymatic synthesis of amoxicillin at $\mathrm{pH} 6.5$ and $25^{\circ} \mathrm{C}$ with $50 \mathrm{mM}$ of $6-\mathrm{APA}$ reacting with $50 \mathrm{mM}$ of PHPGME in the presence of $1 \mathrm{~g}$ of $30 \mathrm{IU} / \mathrm{ml}$ PGA.

C.3 Experimental data for the enzymatic synthesis of amoxicillin at $\mathrm{pH} 6.5$ and $25^{\circ} \mathrm{C}$ with $5 \mathrm{mM}$ of 6-APA reacting with $80 \mathrm{mM}$ of PHPGME in the presence of $1 \mathrm{~g}$ of $30 \mathrm{IU} / \mathrm{ml}$ PGA.

C.4 Experimental data for the enzymatic synthesis of amoxicillin at $\mathrm{pH} 6.5$ and $25^{\circ} \mathrm{C}$ with $5 \mathrm{mM}$ of 6-APA reacting with $5 \mathrm{mM}$ of PHPGME in the presence of $1 \mathrm{~g}$ of $30 \mathrm{IU} / \mathrm{ml}$ PGA. 


\section{NOMENCLATURE}

Components of the reaction:

AMOXI

PHPGME

6-APA

PGA

PGME

PHPG

Other symbols:

$\mathrm{C}_{i}$

$\mathrm{e}_{t}$

E

ES

$\mathrm{k}_{\text {cat } 1}$

$\mathrm{k}_{\text {cat2 }}$

$\mathrm{k}_{\mathrm{i}}$

$\mathrm{K}_{\mathrm{ENZYME}}$

$\mathrm{K}_{\mathrm{m}}$

$\mathrm{K}_{\mathrm{m} 1}$
Amoxicillin

$p$-hydroxyphenylglycine methyl ester

6-aminopenicillanic acid

Penicillin $\mathrm{G}$ acylase

Phenylglycine methylester

p-hydroxy-phenylglycine

Concentration of component $i(\mathrm{mM})$

Fractional error at time $t$

Enzyme

Enzyme-Substrate complex

Rate constant to PHPGME hydrolysis (1/min)

Rate constant to amoxicillin hydrolysis ( $1 / \mathrm{min})$

Kinetic rate constant for component $i(\mathrm{mM})$

Nucleus adsorption constant (mM)

Michaelis-Menten constant (mM)

Michaelis-Menten constant for PHPGME hydrolysis (mM) 
$\mathrm{K}_{\mathrm{m} 2}$

$\mathbf{P}$

$\mathrm{r}_{\text {AMOXI, hydrolysis }}$

$\mathrm{r}_{\mathrm{AMOXI}, \text { synthesis }}$

$\mathrm{r}_{\text {PHPGME, hydrolysis }}$

$\mathrm{R}_{\max }$

$\mathrm{S}$

$\mathrm{V}_{0}$

$\mathrm{V}_{\max }$
Michaelis-Menten constant for amoxicillin hydrolysis (mM)

Product

Rate of amoxicillin hydrolysis ( $\mathrm{mM} / \mathrm{min}$ )

Rate of amoxicillin synthesis ( $\mathrm{mM} / \mathrm{min}$ )

Rate of PHPGME hydrolysis ( $\mathrm{mM} / \mathrm{min}$ )

Maximum conversion ratio of complex acyl-enzyme-nucleus into amoxicillin (-)

Substrate

Initial rate of reaction $(\mathrm{mM} / \mathrm{min})$

Maximum rate of reaction $(\mathrm{mM} / \mathrm{min})$ 


\section{CHAPTER 1: INTRODUCTION}

Amoxicillin is a semi synthetic antibiotic. It is an antibacterial agent with a broad spectrum of bactericidal activity against Gram-positive microorganisms and many Gram-negative pathogens. Organisms, which are characterized by having as part of their cell wall structure peptidoglycans as well as polysaccharides, are called gram-positive organisms. Amoxicillin is soluble in water and practically insoluble in ethanol (96\%), chloroform, ether and other organic solvents. It dissolves in dilute solutions of acids and of alkali hydroxides. It has a convenient three times daily dosage schedule and is rapidly absorbed from the stomach to achieve consistently high blood levels. Physically, amoxicillin is a white or almost white crystalline powder, which is odorless when pure and has a bitter taste. High humidity and high temperature adversely affect its stability. Amoxicillin has now replaced ampicillin on the world health organization's (WHO) essential drugs list for oral use.

Today, many pharmaceuticals are semi-synthetic molecules produced by a reaction between a chemical and a compound that is synthesized by some microorganism. Amoxicillin is also produced by the same mechanism in almost all pharmaceutical plants in the world. In this chemical synthesis, an amino $\beta$-lactam such as 6-aminopenicillanic acid (6-APA), produced by an enzymatic process, is reacted (keeping its carboxyl group protected) with an activated side-chain derivative. This reaction is followed by a reaction that removes the protecting group by hydrolysis and produces amoxicillin. Unfortunately this chemical synthesis has two major drawbacks, first is the costly reaction steps that require a temperature of approximately minus thirty degrees Celsius. The second and more important drawback is 
that the reaction involves toxic organic solvents such as methylene chloride and silylation reagents (Goncalves et al., 2002).

Scientists are consequently trying to find an alternate method for the synthesis of amoxicillin, which would eliminate the need for these toxic organic solvents. Enzymatic synthesis is one of the possible substitutes in which penicillin G acylase (PGA) is used as biocatalyst. PGA is basically an enzyme which can be produced by a variety of microorganisms such as bacteria, fungi and yeast but that from Escherichia coli is found to be the best characterized enzyme of the $\beta$-lactam acylase family (Martin et al., 1995). The production of PGA is a fermentative process with either mutated or natural variant strains (Bock et al., 1983). The use of recombinant $E$. coli eliminates various problems encountered on PGA production such as catabolic repression effect by glucose, fructose, lactose and other carbon sources (Kheirolomoom et al., 2001).

The enzymatic synthesis of amoxicillin can reduce the number of reaction steps and decrease the amount and toxicity of waste products per $\mathrm{kg}$ of antibiotic (Kaasgaard and Veitland, 1996). The use of PGA as biocatalyst displays high selectivity, specificity and activity under mild reaction conditions (aqueous environment, neutral $\mathrm{pH}$ and moderate temperature). These characteristics preclude the use of organic solvents as well as the need for the sequence of protection or unprotection of reactive groups, low temperature and chemical acylation of the chemical synthesis route for the production of amoxicillin. It is not just a simple matter of finding the right enzyme, although no one doubts that bacterial 
enzymes are efficient biocatalysts. The actual goal is to increase the yield of amoxicillin during the enzymatic reaction that would be acceptable for the pharmaceutical industry.

The process for the enzymatic production of amoxicillin has only taken its first steps and several technical barriers still need to be overcome for the enzymatic route to be accepted as an industrial process. To better understand the enzymatic synthesis of amoxicillin, we should know the reaction scheme for this enzymatic reaction, depicted in Fig 1.1.

\subsection{ENZYMATIC SYNTHESIS OF AMOXICILLIN}

The enzymatic reaction for the synthesis of amoxicillin takes place between $p$-hydroxyphenylglycine methyl ester (PHPGME) and 6-aminopenicillanic acid (6-APA) and is catalyzed by PGA immobilized onto glyoxyl-agarose gel beads (Goncalves et al., 2000). This enzymatic reaction is carried out in a jacketed, stirred tank batch bioreactor with mechanical stirring at pH 6.5 and $25^{\circ} \mathrm{C}$ (Goncalves et al., 2000).

The rates of enzymatic reaction generally accelerate on heating but heat can destabilize the enzyme. Consequently, an improvement in enzyme stability is an important step from a practical standpoint (Klibanov, 1983). Since PGA is not stable at $25^{\circ} \mathrm{C}$ it is used as an immobilized form during the reaction. Immobilization of PGA onto glyoxyl-agarose gel gives improved stability and catalytic properties as compared to the native enzyme (Guisan,

1988; Lafuente et al., 1992; Vikartovska et al., 1998). Factors that may play a role in the 
choice of biocatalyst and in the immobilization method to be used are extensively reviewed in the literature (e.g., Bickerstaff, 1997; Clark, 1994; Freeman and Lilly, 1998).

Beside this synthesis reaction producing amoxicillin, PGA also hydrolyzes two undesirable side reactions. First reaction is the hydrolysis of the reactant PHPGME into $p$-hydroxyphenylglycine (PHPG) and methanol $\left(\mathrm{CH}_{3} \mathrm{OH}\right)$. The second reaction is the hydrolysis of the product (amoxicillin, AMOXI) producing more PHPG and recycling part of the other reactant 6-APA. It is very important to try to inhibit these two hydrolysis reactions to achieve maximum yield of amoxicillin (Goncalves et al., 2000).

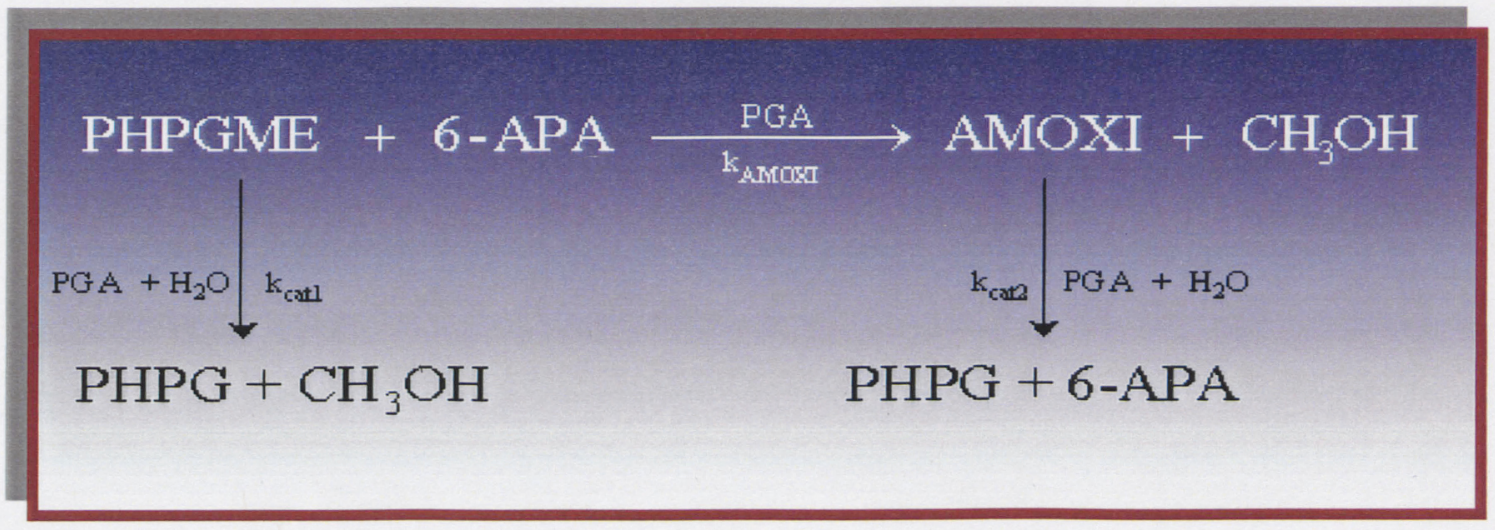

Figure 1.1 Enzymatic synthesis of amoxicillin with side reactions (Goncalves et al., 2000)

\subsection{OBJECTIVE}

The main objective of this research was to simulate a kinetic model for the enzymatic production of amoxicillin to predict how a change in substrate and enzyme concentration acts during the reaction and to suggest conditions that could minimize the undesirable hydrolysis reactions in order to increase the final yield of amoxicillin. 
This kinetic model was presented by the research group of Goncalves for the enzymatic reaction between PHPGME and 6-APA in the presence of PGA (Goncalves et al., 2002). The current developments on the enzymatic synthesis of semi synthetic antibiotics like amoxicillin and ampicillin will be discussed in the next chapter where a literature review will also show which parameters are responsible for the amoxicillin yield and how this yield can be increased during the enzymatic production. 


\section{CHAPTER 2: LITERATURE REVIEW ，}

Today, the enzymatic synthesis of amoxicillin has a wide interest amongst many researchers and pharmaceutical companies. Scientists have tried to produce amoxicillin with the same approaches used for the enzymatic synthesis of other semi synthetic antibiotics like ampicillin and caphalexin that are either synthesized as thermodynamically controlled or kinetically controlled processes (Goncalves et al., 2003). These two approaches for the enzymatic production of amoxicillin are the focus of this review. Since the chemical structure and the enzymatic reaction kinetics of ampicillin are quite similar to that of amoxicillin, the enzymatic production of ampicillin is also reviewed to get some ideas of what conditions could be imported into the synthesis of amoxicillin.

\subsection{THERMODYNAMICALLY CONTROLLED SYNTHESIS}

Thermodynamically controlled synthesis is a reverse reaction of antibiotic hydrolysis. It is a simpler strategy than the kinetically controlled synthesis for the enzymatic production of semi synthetic antibiotics. It is based on the direct condensation of an antibiotic nucleus and a non-activated acyl donor. Antibiotic production is determined by the thermodynamic equilibrium constant of the process. Enzyme does not influence the equilibrium state of the reaction but it only affects the rate at which the equilibrium is established. This strategy can only be applied successfully if thermodynamics of reverse hydrolysis reaction is favorable and concentration of the product that is formed exceeds its solubility. Then a suspension of 
solid substrates can be converted into a suspension of solid products. This situation, which is called 'solid-to-solid' process, has been achieved for several enzymatic reactions (Kasche, 1986; Halling et al., 1995).

During thermodynamically controlled synthesis of amoxicillin, the thermodynamics of reverse hydrolysis reaction is unfavorable in aqueous medium. An increase in substrate concentration up to the solubility level or even higher results in the suspension of the substrate, and the addition of water miscible organic solvents are required to shift the reaction equilibrium towards synthesis (Kim and Lee, 1996; Tewari et al., 1995).

In 1998, Diender and coworkers studied the feasibility of solid-to-solid conversion for the enzymatic, thermodynamically controlled synthesis of amoxicillin in aqueous solution. They reported that the final concentration of amoxicillin remained lower than its solubility in aqueous solution. Adding organic solvents in monophasic systems could improve the production in enzymatic condensation reactions. But since the removal of organic solvents during the production of amoxicillin is the actual goal, this 'solid-to-solid' thermodynamically controlled synthesis of amoxicillin in aqueous solution was not recommended (Diender et al., 1998).

\subsection{KINETICALLY CONTROLLED SYNTHESIS}

The kinetically controlled synthesis is the most frequently applied strategy for the production of semi synthetic antibiotics, in which an activated acyl donor is coupled to an 
antibiotic nucleus to produce the antibiotic (Diender et al., 1998). The balance between three different catalytic activities of the same enzyme determines the final concentration of the antibiotic (Goncalves et al., 2003). These are:

1- Synthesis of the product, amoxicillin

2- Hydrolysis of the activated acyl donor, $p$-hydroxyphenylglycine methyl ester

3- Hydrolysis of the product, amoxicillin

The last two hydrolysis steps were mentioned in Figure 1.1. In 2000, the research group of Goncalves studied the kinetics of the enzymatic synthesis of amoxicillin from PHPGME and 6-APA using PGA as catalyst immobilized on glyoxyl-agarose gel beads. They performed batch experiments at various stirring speeds and with varying bead particle diameters and pore sizes to investigate the existence of external mass transport limitations. To avoid the interference of intragel diffusion, they used low enzyme load during immobilization. Concentration profiles remained constant regardless of stirring speed and pore sizes. They also proposed a kinetic model based on the assumption that the synthesis of amoxicillin requires prior adsorption of its nucleus (6-APA) to the active center of the enzyme. They compared their simulation results with experimental data to validate the proposed kinetic model. They reported that the model was valid for the first 100 minutes of synthesis and failed to predict amoxicillin production after that time.

In 2002, Goncalves and co-workers developed another model for the enzymatic kinetically controlled synthesis of amoxicillin and studied the role of 6-APA on the kinetics of 
amoxicillin enzymatic synthesis catalyzed by PGA immobilized onto glyoxyl-agarose gel. This model was validated over a wide range of initial substrate concentrations, from 50 to $100 \mathrm{mM}$ of 6-APA at $\mathrm{pH} 6.5$ and $25^{\circ} \mathrm{C}$.

In 2003, Goncalves and his collaborators studied inhibitory effects during the synthesis of amoxicillin, the hydrolysis of PHPGME and the hydrolysis of amoxicillin. They proposed a kinetic model that included various inhibitory effects in the rate equations. They reported that PHPGME and amoxicillin behaved as inhibitors of the hydrolysis of amoxicillin and PHPGME, respectively, and that 6-APA acted as inhibitor of the hydrolysis of amoxicillin.

In 1996, the research group of Ospina studied the effect of $\mathrm{pH}$ from 5.5 to 8.0 on the synthesis of ampicillin by phenylglycine methylester (PGME) and 6-APA, catalyzed by penicillin acylase. This enzymatic reaction for the synthesis of ampicillin also contains hydrolysis reactions for PGME and ampicillin, similar to those found during the synthesis of amoxicillin. They found that up to $75 \%$ conversion of ampicillin could occur by selectively inhibiting the hydrolysis of PGME by: a) controlling the $\mathrm{pH}$ at 6.0 , and $\mathrm{b}$ ) using 6-APA solutions ranging from $50-200 \mathrm{mM}$. They also reported that by controlling the $\mathrm{pH}$ it was possible to inhibit the undesirable hydrolysis reactions of PGME and ampicillin, increasing the yield of the main reaction. At pH 7.0, the synthesis of ampicillin occurred slowly compared to the other two hydrolysis reactions. Because of the high rate of hydrolysis, ampicillin accumulation was non existent. Since PGME is a substrate that can easily be hydrolyzed at higher $\mathrm{pH}$, a high concentration of PGME is required to overcome this problem. 
They went on to describe the reaction kinetics for the ampicillin synthesis with experimentally determined Michaelis-Menten constants at $\mathrm{pH} 6.0$ and developed a kinetic model for this enzymatic synthesis reaction. A good correlation was reported between experimental data and the kinetic model derived from initial rate experiments with only slight deviations at high substrate concentrations.

In conclusion, we can say that to find a better yield of amoxicillin for its enzymatic synthesis we still need to find the optimum reaction conditions and parameters. Also we need a good understanding about the enzymatic reaction kinetics of this complex enzymatic reaction. The next chapter will discuss the kinetics of enzymatic reaction for the synthesis of amoxicillin. 


\section{CHAPTER 3: KINETICS OF ENZYME-CATALYZED REACTIONS}

Enzymes are usually very selective catalysts. A particular enzyme can catalyze only specific reactions or very specific substrate molecules. Reactants are commonly known as substrates in biochemical reactions. Like all other enzymes PGA is a protein molecule, which acts as a catalyst in the enzymatic reaction between PHPGME and 6-APA for the production of amoxicillin. This enzymatic reaction follows Michaelis-Menten kinetics, according to Goncalves et al. (2002).

\subsection{MICHAELIS-MENTEN KINETICS}

The catalytic event that enzymatically converts one or more substrates to product(s) normally proceeds by formation of an enzyme-substrate complex in which the substrate is bound to a specific region of the enzyme called the active site. The enzyme-substrate complex dissociates to yield the product(s) of the catalyzed reaction and regenerates the enzyme. Experimentally, it has been found that the rates of many enzyme-catalyzed reactions are directly proportional to the substrate concentration when the latter is low and become independent of substrate concentration as the latter increases. This behavior is said to follow Michaelis-Menten kinetics in honor of Leonor Michaelis and Maud Menten who proposed the kinetic mechanism in 1913 . This can be simply illustrated by the following reaction sequence (Bailey and Ollis, 1986):

Enzyme + Substrate $\longleftrightarrow$ (Enzyme - Substrate complex $) \longrightarrow$ Enzyme + Product 
Using the usual biochemical symbols for substrate $(\mathrm{S})$, enzyme $(\mathrm{E})$, products $(\mathrm{P})$, and enzyme-substrate complex (ES), the above mechanism can be written as:

$$
\mathrm{E}+\mathrm{S} \underset{\mathrm{k}_{-1}}{\stackrel{\mathrm{k}_{1}}{\longrightarrow}} \mathrm{ES} \stackrel{\mathrm{k}_{2}}{\longrightarrow} \mathrm{E}+\mathrm{P}
$$

where $k_{1}, k_{-1}$ and $k_{2}$ are the respective rate constants. Following the Michaelis-Menten kinetics, PHPGME first reacts with enzyme (PGA) to produce an acyl-enzyme complex, which then reacts with 6-APA to give amoxicillin (Goncalves et al., 2002).

In equation 3.1, the second reaction is rate limiting and at very high substrate concentration almost all enzyme is present as enzyme-substrate complex. Under these conditions a steady state is reached in which the enzyme is saturated by the substrate and the initial rate of reaction $\left(\mathrm{V}_{0}\right)$ is at a maximum $\left(\mathrm{V}_{\max }\right)$. This relation between substrate concentration and reaction rate is described by the Michaelis-Menten equation (Bailey and Ollis, 1986):

$$
\mathrm{V}_{0}=\frac{\mathrm{V}_{\max } \mathrm{S}}{\mathrm{K}_{\mathrm{m}}+\mathrm{S}}
$$

where $K_{m}$ is the Michaelis constant of the enzyme for the given substrate and may also be described by:

$$
\mathrm{K}_{\mathrm{m}}=\frac{\mathrm{k}_{-1}+\mathrm{k}_{2}}{\mathrm{k}_{1}}
$$

Note that $\mathrm{K}_{\mathrm{m}}$ is like an equilibrium constant but it is not a real one. It is a ratio of the rate constants for the loss of [ES] divided by the rate constant for its production. Therefore the value of $\mathrm{K}_{\mathrm{m}}$ can also be written as: 


$$
\mathrm{K}_{\mathrm{m}}=\frac{[\mathrm{E}][\mathrm{S}]}{[\mathrm{ES}]}
$$

Goncalves and coworkers (Goncalves et al., 2002) used the above equations 3.2 to 3.4 to calculate Michaelis-Menten constants for the hydrolysis of PHPGME $\left(\mathrm{K}_{\mathrm{m} 1}\right)$ and amoxicillin $\left(\mathrm{K}_{\mathrm{m} 2}\right)$, as will be seen in Chapter 4 .

\subsection{ENZYME ACTIVITY AND ENZYME CONCENTRATION}

In addition to $\mathrm{K}_{\mathrm{m}}$ and $\mathrm{V}_{\max }$, the turnover number and the specific activity are important parameters for the characterization of enzyme reactions. Both are determined under substrate saturation. With highly purified enzymes the turnover number reflects the number of substrate molecules converted into product per minute by a single enzyme molecule (Bailey and Ollis, 1986). The specific activity of enzymes is given in international units (IU), with 1 IU being the amount of enzyme consuming $1 \mu \mathrm{mol}$ substrate or forming $1 \mu \mathrm{mol}$ product per minute. So, in the presence of 1 IU of enzyme, the rate of reaction is 1 $\mu \mathrm{mol} / \mathrm{min}$.

For PGA, 1 IU corresponds to the amount of enzyme that hydrolyzes $1 \cdot \mu \mathrm{mol}$ of penicillin $\mathrm{G}$ ( $5 \%$ mass/volume) per minute at $\mathrm{pH} 8.0$ and $38^{\circ} \mathrm{C}$. Goncalves and coworkers (Goncalves et al., 2002) immobilized 30 IU PGA per ml of glyoxyl-agarose gel and used one gram of that mixture as a beaded catalyst for the enzymatic reaction producing amoxicillin. 


\section{3 pH DEPENDENCE OF ENZYMES}

Each enzyme has an optimum $\mathrm{pH}$ value at which its activity is at a maximum. In the range of this optimum value, proton-donating or proton-accepting groups on the active sites of the enzyme are in the ionized state required for the enzyme to function. Outside this range, substrate binding is not possible, and at extreme $\mathrm{pH}$ values the enzyme can be denatured. The optimum $\mathrm{pH}$ depends on the composition of the medium, reaction temperature, and stability of the enzyme in acid or alkaline environments (Bailey and Ollis, 1986).

So to achieve a maximum yield of amoxicillin, the enzymatic reaction should take place at a $\mathrm{pH}$ where the activity of PGA is a maximum. Also, the right ratio of substrate-to-enzyme concentration is required. In the next chapter, a kinetic model presented by Goncalves and his collaborators will be simulated to visualize the effects of substrate and enzyme concentrations during the reaction. 


\section{CHAPTER 4: KINETIC MODEL AND SIMULATION}

As stated in literature review, the research group of Goncalves (Goncalves et al., 2002) proposed a kinetic model for the enzymatic reaction between PHPGME and 6-APA, catalyzed by PGA immobilized on glyoxyl-agarose gel beads for the synthesis of amoxicillin. They used this model to study the role of 6-APA concentration during the enzymatic production of amoxicillin. In the present work this model was used to predict how increased concentration of enzyme and substrate acts during this enzymatic reaction. The model is based on the following assumptions:

\subsection{ASSUMPTIONS FOR THE KINETIC MODEL}

1- The synthesis of amoxicillin only occurs when 6-APA is reacted with previously bounded acyl-enzyme complex (PHPGME-enzyme).

2- The rate of formation of this acyl-enzyme complex is not influenced by the presence of 6-APA.

\subsection{MODEL EQUATIONS}

The formation of the acyl-enzyme complex is the initial step in the synthesis of amoxicillin. The rate equations for amoxicillin and PHPGME hydrolyses, and for amoxicillin synthesis are presented in equations 4.1 to 4.3 respectively (Goncalves et al., 2002). 
The rate of amoxicillin hydrolysis $\left(\mathrm{r}_{\mathrm{AMOXI}}\right.$, hydrolysis $)$ is given by:

$$
\mathrm{r}_{\mathrm{AMOXI} \text { hydrolysis }}=\frac{\mathrm{k}_{\mathrm{cat} 2} \mathrm{C}_{\mathrm{AMOXI}} \mathrm{C}_{\mathrm{ENZYME}}}{\mathrm{K}_{\mathrm{m} 2}\left(1+\left(\mathrm{C}_{\mathrm{PHPGME}} / \mathrm{k}_{\mathrm{PHPGME}}\right)+\left(\mathrm{C}_{6-\mathrm{APA}} / \mathrm{k}_{6-\mathrm{APA}}\right)+\left(\mathrm{C}_{\mathrm{PHPG}} / \mathrm{k}_{\mathrm{PHPG}}\right)\right)+\mathrm{C}_{\mathrm{AMOXI}}} . .4 .1
$$

where

$\begin{array}{lll}\mathrm{k}_{\mathrm{cat} 2} & = & \text { Rate constant to amoxicillin hydrolysis }(1 / \mathrm{min}) \\ \mathrm{K}_{\mathrm{m} 2} & = & \text { Michaelis-Menten constant for amoxicillin hydrolysis }(\mathrm{mM}) \\ \mathrm{C}_{\mathrm{AMOXI}} & = & \text { Concentration of amoxicillin }(\mathrm{mM}) \\ \mathrm{C}_{\mathrm{ENZYME}} & = & \text { Concentration of enzyme }(\mathrm{mM}) \\ \mathrm{C}_{\mathrm{PHPGME}} & = & \text { Concentration of PHPGME }(\mathrm{mM}) \\ \mathrm{C}_{\mathrm{PHPG}} & = & \text { Concentration of PHPG }(\mathrm{mM}) \\ \mathrm{k}_{\mathrm{AMOXI}} & = & \text { Kinetic rate constant for amoxicillin }(\mathrm{mM}) \\ \mathrm{k}_{\mathrm{PHPME}} & = & \text { Kinetic rate constant for PHPGME inhibition }(\mathrm{mM}) \\ \mathrm{k}_{\mathrm{PHPG}} & = & \text { Kinetic rate constant for PHPG }(\mathrm{mM}) \\ \mathrm{k}_{6-\mathrm{APA}} & = & 6-\mathrm{APA} \text { adsorption constant }(\mathrm{mM})\end{array}$

The rate of PHPGME hydrolysis $\left(r_{\text {PHPGME, hydrolysis }}\right)$ is given by:

$\mathrm{r}_{\mathrm{PHPGME} \text {, hydrolysis }}=\frac{\mathrm{k}_{\text {catl }} \mathrm{C}_{\mathrm{PHPGME}} \mathrm{C}_{\mathrm{ENZYME}}}{\mathrm{K}_{\mathrm{ml}}\left(1+\left(\mathrm{C}_{\mathrm{AMOXI}} / \mathrm{k}_{\mathrm{AMOXI}}\right)+\left(\mathrm{C}_{\mathrm{PHPG}} / \mathrm{k}_{\mathrm{PHPG}}\right)\right)+\mathrm{C}_{\mathrm{PHPGME}}}$

where
$\mathrm{k}_{\text {cat } 1}$
$=\quad$ Rate constant to PHPGME hydrolysis $1 / \mathrm{min}$ )
$\mathrm{K}_{\mathrm{m} 1}$
$=\quad$ Michaelis-Menten constant for PHPGME hydrolysis (mM) 
And the rate of amoxicillin synthesis $\left(\mathrm{r}_{\mathrm{AMOXI} \text {,synthesis }}\right)$ is given by:

$\mathrm{r}_{\mathrm{AMOXI} \text {, synthesis }}=\frac{\mathrm{k}_{\text {catl }} \mathrm{C}_{\mathrm{PHPGME}} \mathrm{C}_{\mathrm{ENZYME}}}{\mathrm{K}_{\mathrm{ml}}\left(1+\left(\mathrm{C}_{\mathrm{AMOXI}} / \mathrm{k}_{\mathrm{AMOXI}}\right)+\left(\mathrm{C}_{\mathrm{PHPG}} / \mathrm{k}_{\mathrm{PHPG}}\right)\right)+\mathrm{C}_{\mathrm{PHPGME}}} \mathrm{R}_{\max } \mathrm{X} \ldots \ldots \ldots . . .4 .3$

where

$$
\begin{aligned}
\mathrm{X}= & \frac{\mathrm{C}_{6-\mathrm{APA}}}{\mathrm{K}_{\mathrm{ENZYME}}+\mathrm{C}_{6-\mathrm{APA}}} \\
\mathrm{R}_{\max =} & \text { Maximum conversion ratio of the complex acyl-enzyme-nucleus } \\
& \text { into amoxicillin }(-) \\
\mathrm{K}_{\mathrm{ENZYME}}= & \text { Nucleus adsorption constant (mM) }
\end{aligned}
$$

\subsection{MASS BALANCE EQUATIONS}

The mass balance equations for the model are given below (Goncalves et al., 2002):

$\frac{\mathrm{dC}_{\text {PHPGME }}}{\mathrm{dt}}=-\mathrm{r}_{\text {PHPGME, hydrolysis }}$

$\frac{\mathrm{dC}_{\mathrm{AMOXI}}}{\mathrm{dt}}=\mathrm{r}_{\mathrm{AMOXI} \text {, synthesis }}-\mathrm{r}_{\mathrm{AMOXI} \text {, hydrolysis }}$

$\frac{\mathrm{dC}_{6-\mathrm{APA}}}{\mathrm{dt}}=\mathrm{r}_{\mathrm{AMOXI}, \text { hydrolysis }}-\mathrm{r}_{\mathrm{AMOXI}, \text { synthesis }}$ 


\subsection{MODEL PARAMETERS}

Parameters for the simulated model are listed in Table 4.1 (Goncalves et al., 2002):

Table 4.1 Value of model parameters at $\mathrm{pH} 6.5$ and $25^{\circ} \mathrm{C}$.

\begin{tabular}{|c|c|}
\hline Parameter & Value \\
\hline $\mathrm{K}_{\mathrm{m} 1}(\mathrm{mM})$ & $7.905 \pm 3.61$ \\
\hline $\mathrm{K}_{\mathrm{m} 2}(\mathrm{mM})$ & $12.509 \pm 3.21$ \\
\hline $\mathrm{k}_{\mathrm{PHPGME}}(\mathrm{mM} / \mathrm{min})$ & $3.78 \pm 0.71$ \\
\hline $\mathrm{k}_{\mathrm{AMOXI}}(\mathrm{mM} / \mathrm{min})$ & $9.174 \pm 2.13$ \\
\hline $\mathrm{k}_{\mathrm{PHPG}}(\mathrm{mM} / \mathrm{min})$ & $10.907 \pm 2.087$ \\
\hline $\mathrm{k}_{6-\mathrm{APA}}(\mathrm{mM} / \mathrm{min})$ & $62.044 \pm 7.51$ \\
\hline $\mathrm{K}_{\mathrm{ENZYME}}(\mathrm{mM})$ & $14.350 \pm 2.13$ \\
\hline $\mathrm{R}_{\max }(-)$ & $0.606 \pm 0.03$ \\
\hline
\end{tabular}

\subsection{FOURTH ORDER RUNGE-KUTTA METHOD}

In this work the kinetic model of Goncalves et al. (2002) was simulated by solving the differential equations (Equations 4.4 - 4.6) with the very popular Fourth Order Runge-Kutta numerical method, using a step size of 0.1 . This method is accurate to the fourth-order term in the Taylor's series expansion. The only disadvantage of this method is that it requires 
several evaluations of $f(x, y)$ for each step of integration, resulting in a somewhat slower than other methods (Rao, 2002). The Fourth Order Runge-Kutta method requires only one initial point to start the procedure. It calculates the slope based on the current value to compute the next value of the function (Chapra and Canale, 2002). See appendix A for a detailed algorithm of the method.

\subsection{VALIDATION OF THE SIMULATION}

Fractional errors between the predicted values obtained from simulation and the experimental data from literature (Goncalves et al., 2002) were calculated as follows:

$$
e_{t}=\left[1-\frac{\text { Simulated value }}{\text { Experimental data }}\right]
$$

Comparisons were also made between the predicted values obtained in this work and the simulation results obtained from literature whenever the initial conditions and reaction parameters were the same. Simulation in which the fractional errors were less than \pm 0.05 was judged to be very good. 


\section{CHAPTER 5: RESULTS AND DISCUSSION}

The Fourth Order Runge-Kutta method was used with a C++ Program (Appendix B) to solve the kinetic model described in Chapter 4. This simulated model predicted the effect of reactant and enzyme concentration during the enzymatic reaction between PHPGME and 6APA in the presence of PGA for the synthesis of amoxicillin. The simulation was performed for the following:

1- Comparison of simulation results with experimental data

2- Prediction of effect of high substrate concentration

3- Prediction of effect of high enzyme concentration

\subsection{COMPARISON OF SIMULATION RESULTS WITH EXPERIMENTAL DATA}

The simulated model was first solved for the same initial conditions and concentrations of PHPGME, 6-APA and PGA at which experimental data (See Appendix C) were available in the literature (Goncalves et al., 2000; 2002; 2003) to validate the simulation results. These simulations were named Case One (100mM of 6-APA; $70 \mathrm{mM}$ of PHPGME), Case Two (50mM of 6-APA; 50mM of PHPGME), Case Three (5mM of 6-APA; 80mM of PHPGME) and Case Four (5mM of 6-APA; 5mM of PHPGME). All experimental data describe runs at pH 6.5 and at $25^{\circ} \mathrm{C}$, with $1 \mathrm{~g}$ of $30 \mathrm{IU} / \mathrm{ml}$ PGA immobilized on glyoxy-agarose gel beads. 


\subsubsection{CASE ONE}

Figure 5.1 shows that simulation performed with $100 \mathrm{mM}$ 6-APA and 70mM PHPGME predicted a plateau in 400 minutes that gave a maximum of $13 \mathrm{mM}$ of amoxicillin (pink curve and data points), which was equivalent to a consumption of $13 \%$ of the initial concentration of 6-APA. The simulation also confirmed a mirror image curve for 6-APA concentration. This mole-to-mole conversion ratio of 6-APA into amoxicillin was set up by equations 4.5 and 4.6 .

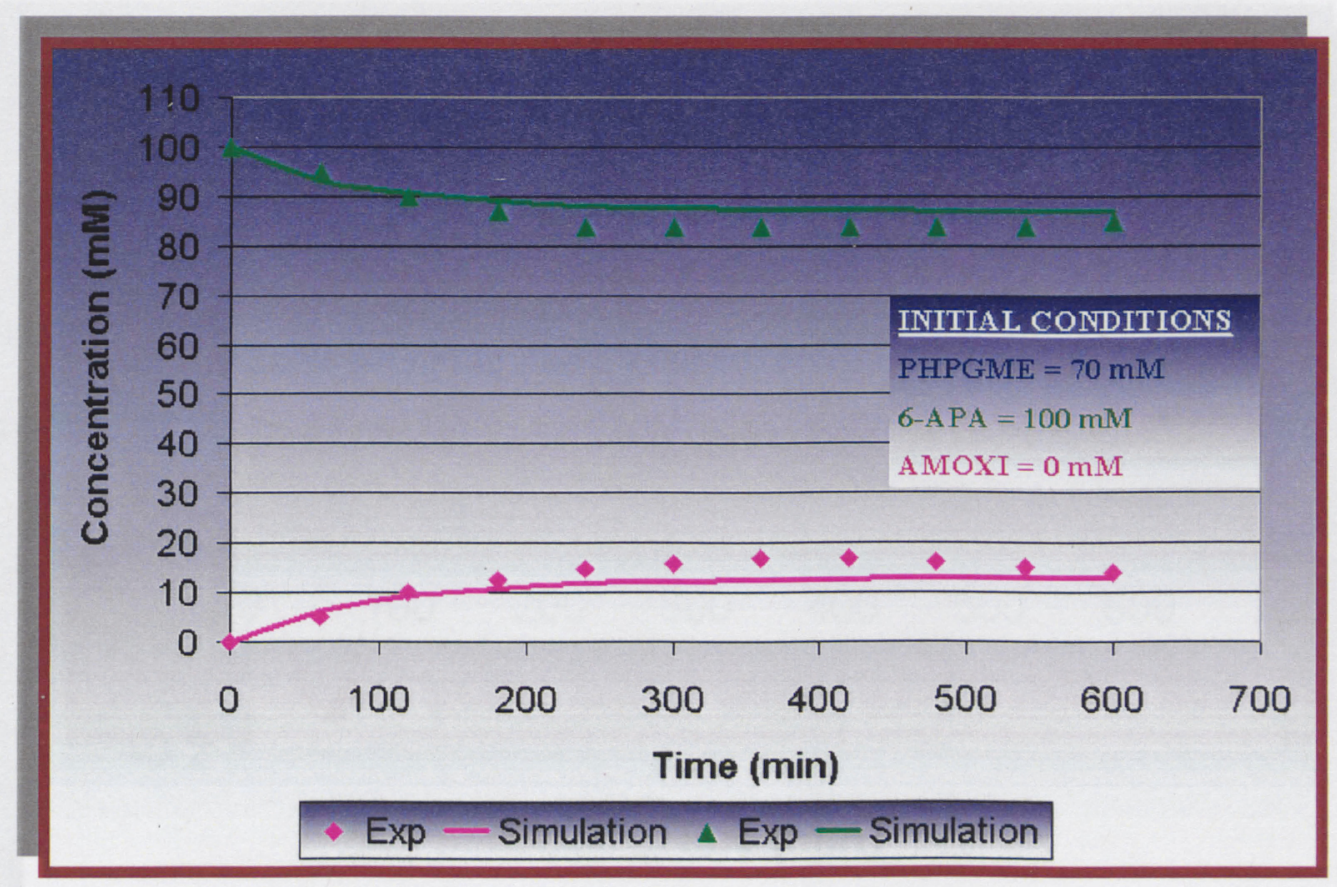

Figure 5.1 Comparison of simulation results with experimental data (Goncalves et al., 2002) at initial concentrations of 100mM 6-APA and 70mM PHPGME. 
To validate the simulation of the kinetic model, plots of the fractional errors against time between the predicted values obtained from fourth order Runga-Kutta simulation and experimental data from literature (Goncalves et al., 2002) were drawn (Figure 5.2). A good correlation $\left(e_{t} \leq \pm 0.05\right)$ was not found for each point but a better correlation was found up to 120 minutes and after 540 minutes. Comparison between the predicted values obtained in this work and the simulation results obtained from literature with same initial conditions and reaction parameters (Goncalves et al., 2002) showed similar behavior (Figure 5.2).

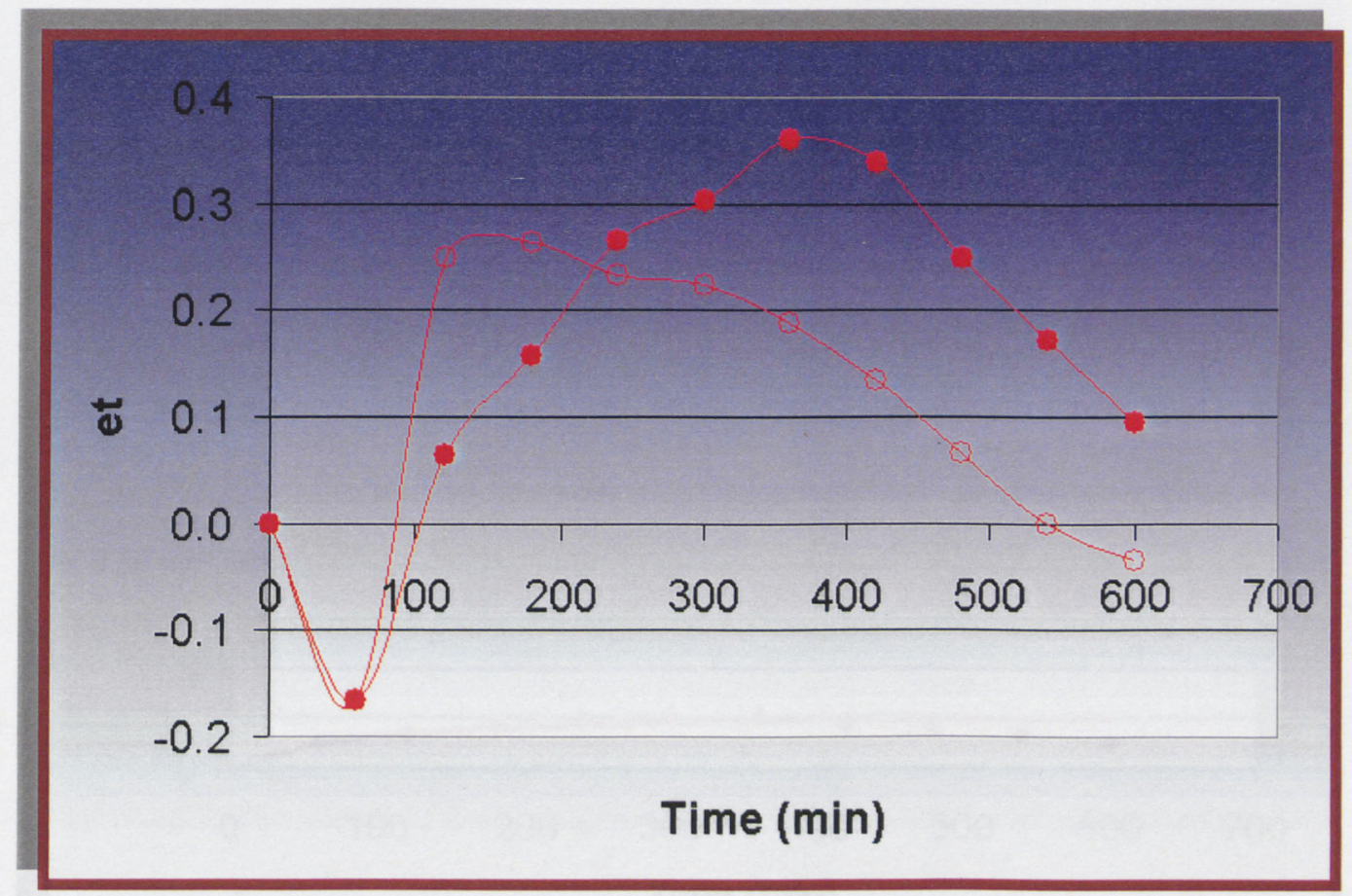

Figure 5.2 Fractional error in simulating experimental amoxicillin concentration (Goncalves et al., 2002) by the Fourth Order Runga-Kutta (•) compared to the literature simulation (०) for 100mM 6-APA and 70mM PHPGME (Case One). 


\subsubsection{CASE TWO}

When the simulation run was performed at equal initial concentrations of $50 \mathrm{mM}$ for both 6 APA and PHPGME (Figure 5.3), a maximum of $10 \mathrm{mM}$ of amoxicillin was predicted in 400 minutes, which was equivalent to a consumption of $20 \%$ of the initial concentration of 6 APA. Experimental data showed a decrease in amoxicillin concentration after 400 minutes but the simulation predicted a plateau. This decrease in amoxicillin concentration results from its hydrolysis, regenerating 6-APA (Fig. 1.1). The production of 6-APA can also be seen after 400 minutes and a mirror image curve was again obtained.

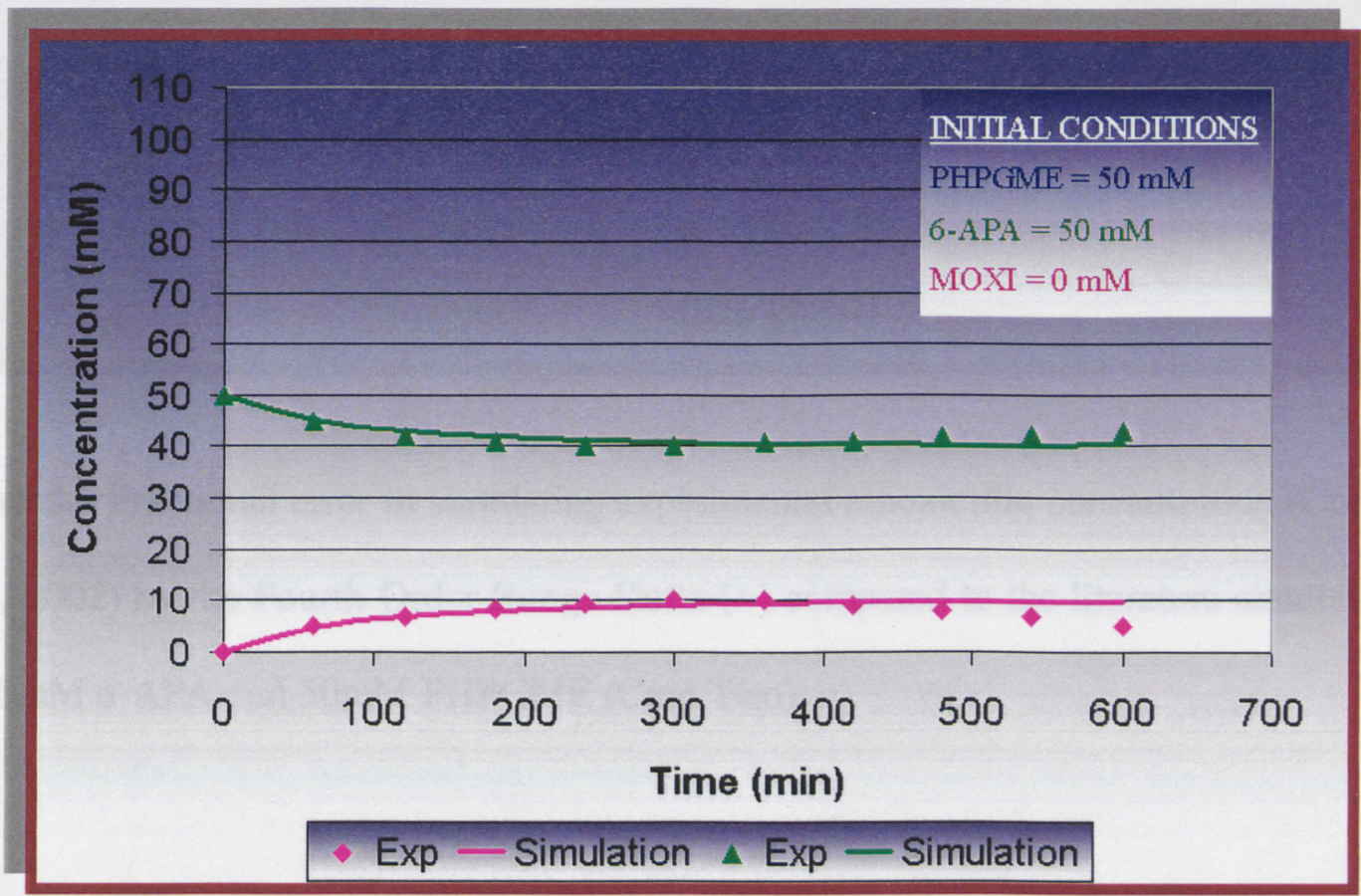

Figure 5.3 Comparison of simulation results with experimental data (Goncalves et al., 2002) at initial concentrations of 50mM 6-APA and 50mM PHPGME. 
Fractional errors for predicted values obtained in this work and the simulation results obtained from literature with same initial conditions and reaction parameter (Goncalves et al., 2002) showed an acceptable correlation up to 420 minutes and after that significant deviation was observed (Figure 5.4).

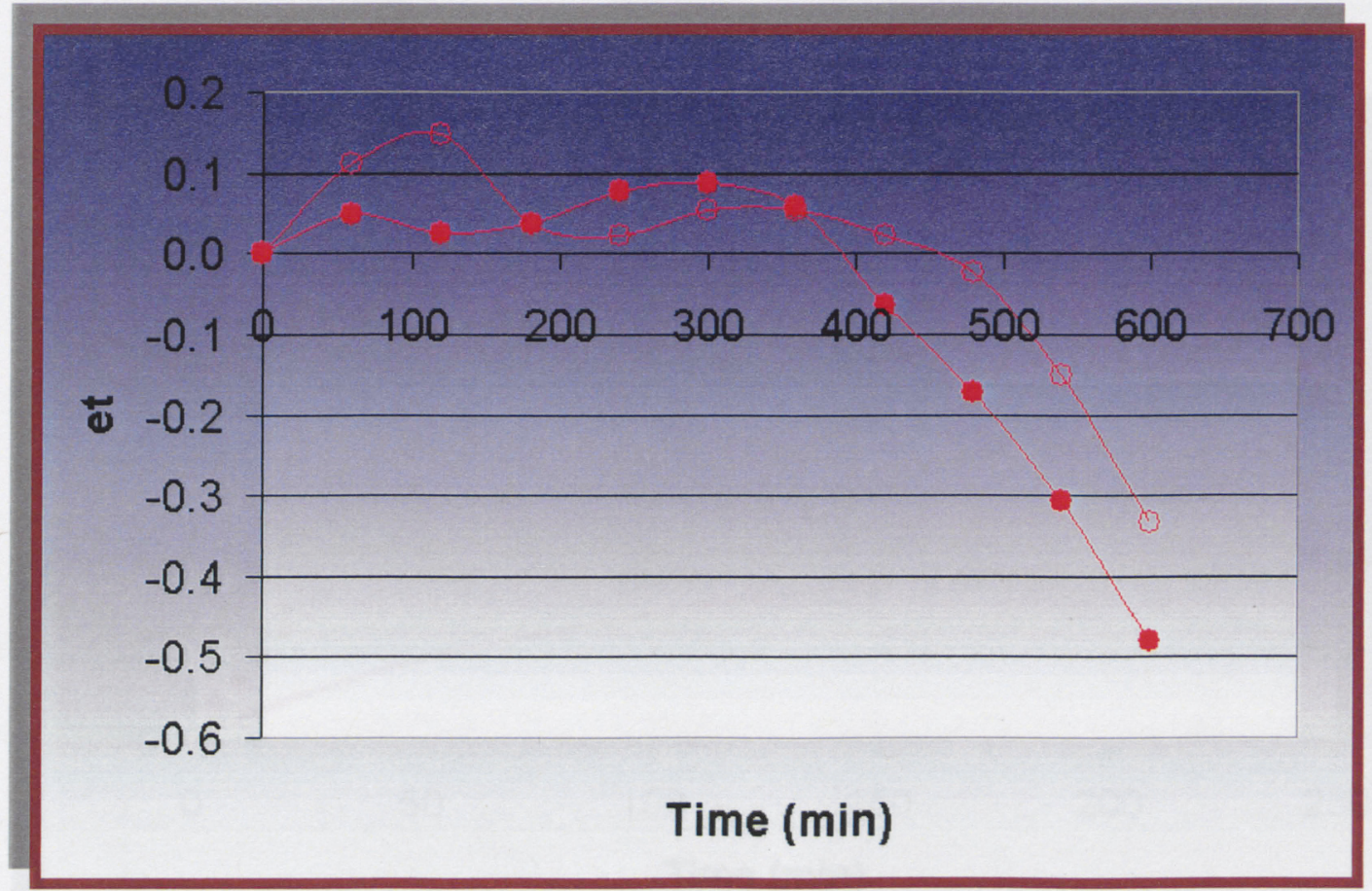

Figure 5.4 Fractional error in simulating experimental amoxicillin concentration (Goncalves et al., 2002) by the Fourth Order Runga-Kutta $(\bullet)$ compared to the literature simulation $(\circ)$ for 50mM 6-APA and 50mM PHPGME (Case Two).

\subsubsection{CASE THREE}

In this case, the simulation model for a high initial concentration (80mM) of PHPGME reacting with $5 \mathrm{mM}$ of 6-APA (Figure 5.5) predicted the maximum amoxicillin 
experimentally obtained, despite predicting more time to achieve it. Both the model and the experimental data showed a maximum amoxicillin yield of $40 \%$ from the initial concentration of 6-APA. The model predicted this maximum after 225 minutes whereas only 60 minutes were necessary in the experimental run. The reactant 6-APA again mirror imaged the amoxicillin profile.

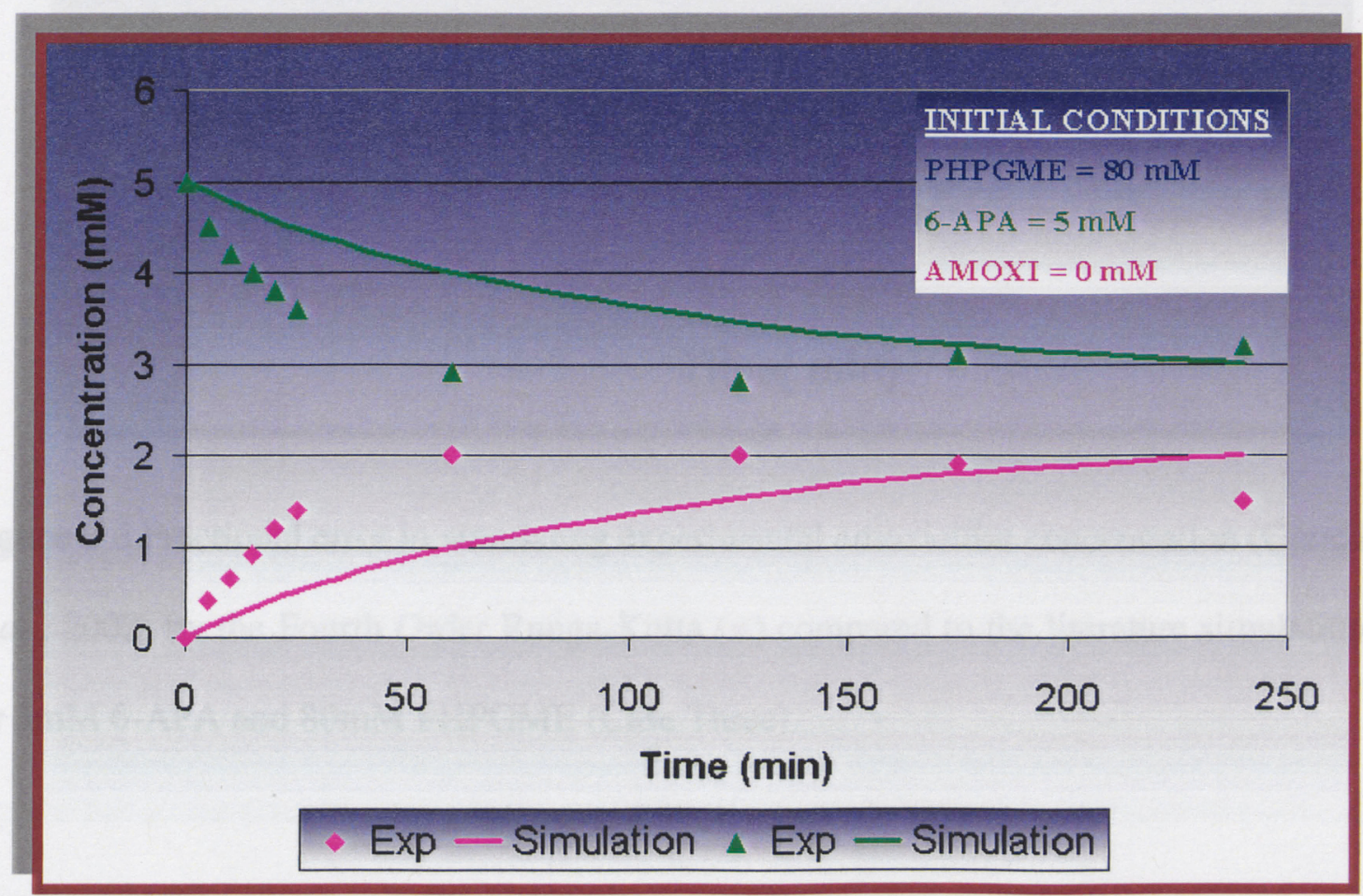

Figure 5.5 Comparison of simulation results with experimental data (Goncalves et al., 2002) at initial concentrations of 5mM 6-APA and 80mM PHPGME.

Fractional errors show that both simulation results, either predicted in this work or obtained from literature at same initial conditions and reaction parameters (Goncalves et al., 2002) underestimated the amoxicillin experimental profile during the first 180 minutes, while after 180 minutes a better correlation was observed (Figure 5.6). 


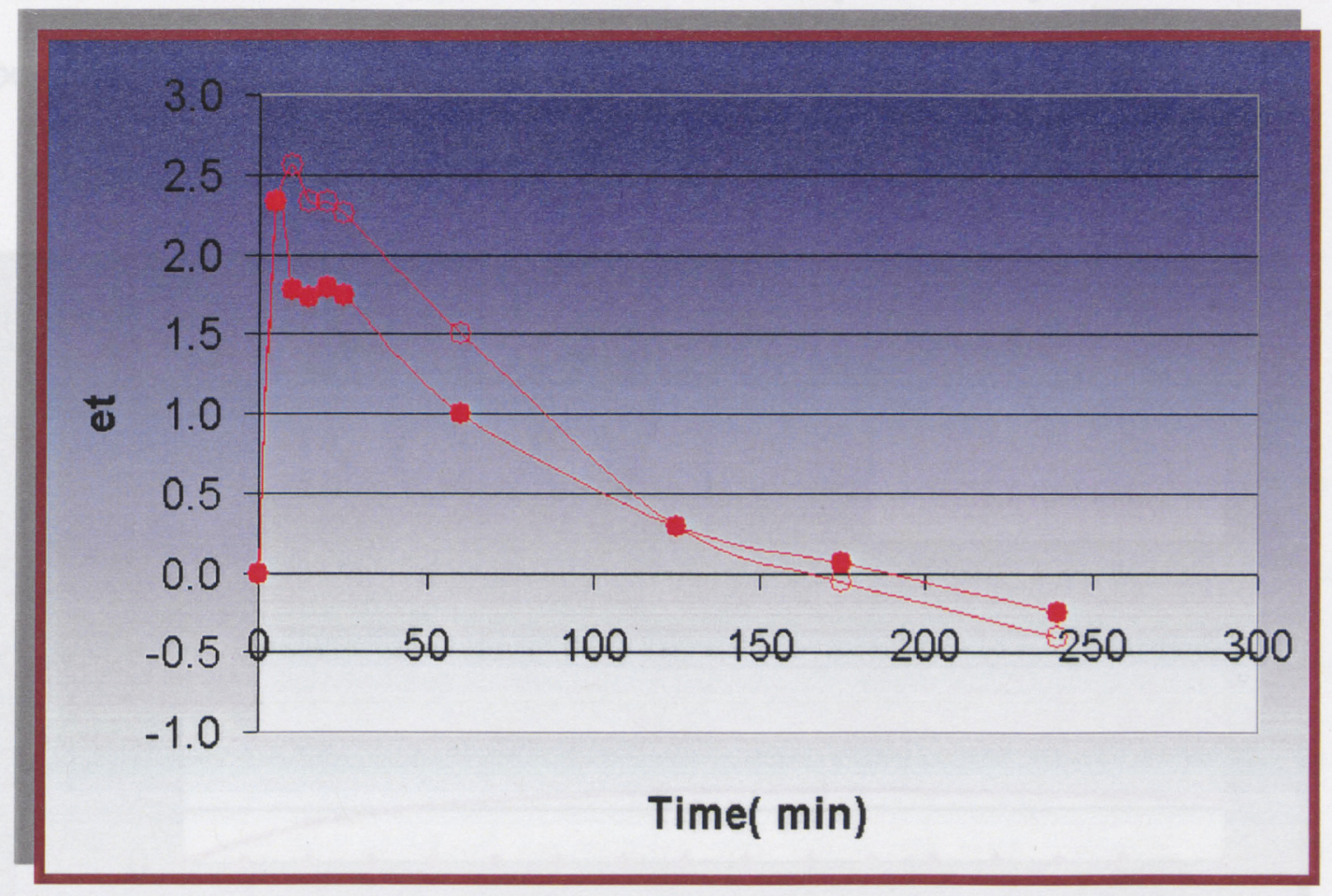

Figure 5.6 Fractional error in simulating experimental amoxicillin concentration (Goncalves et al., 2002) by the Fourth Order Runga-Kutta ( $\bullet$ ) compared to the literature simulation $(\odot)$ for 5mM 6-APA and 80mM PHPGME (Case Three).

\subsubsection{CASE FOUR}

In this case the simulation performed at equal concentrations of $5 \mathrm{mM}$ for both 6-APA and PHPGME (Figure 5.7) showed that the model overestimated the amoxicillin experimental profile. The experimental data showed that no conversion reaction took place at all. A maximum of $1.4 \mathrm{mM}$ amoxicillin was predicted around 600 minutes. Similarly, 6-APA remained constant in the experimental run, whereas the simulation predicted a conversion 
equivalent to $1.4 \mathrm{mM}$. Since there was no conversion reported in experimental data, it was not possible to compare simulation results between Runga-Kutta and literature.

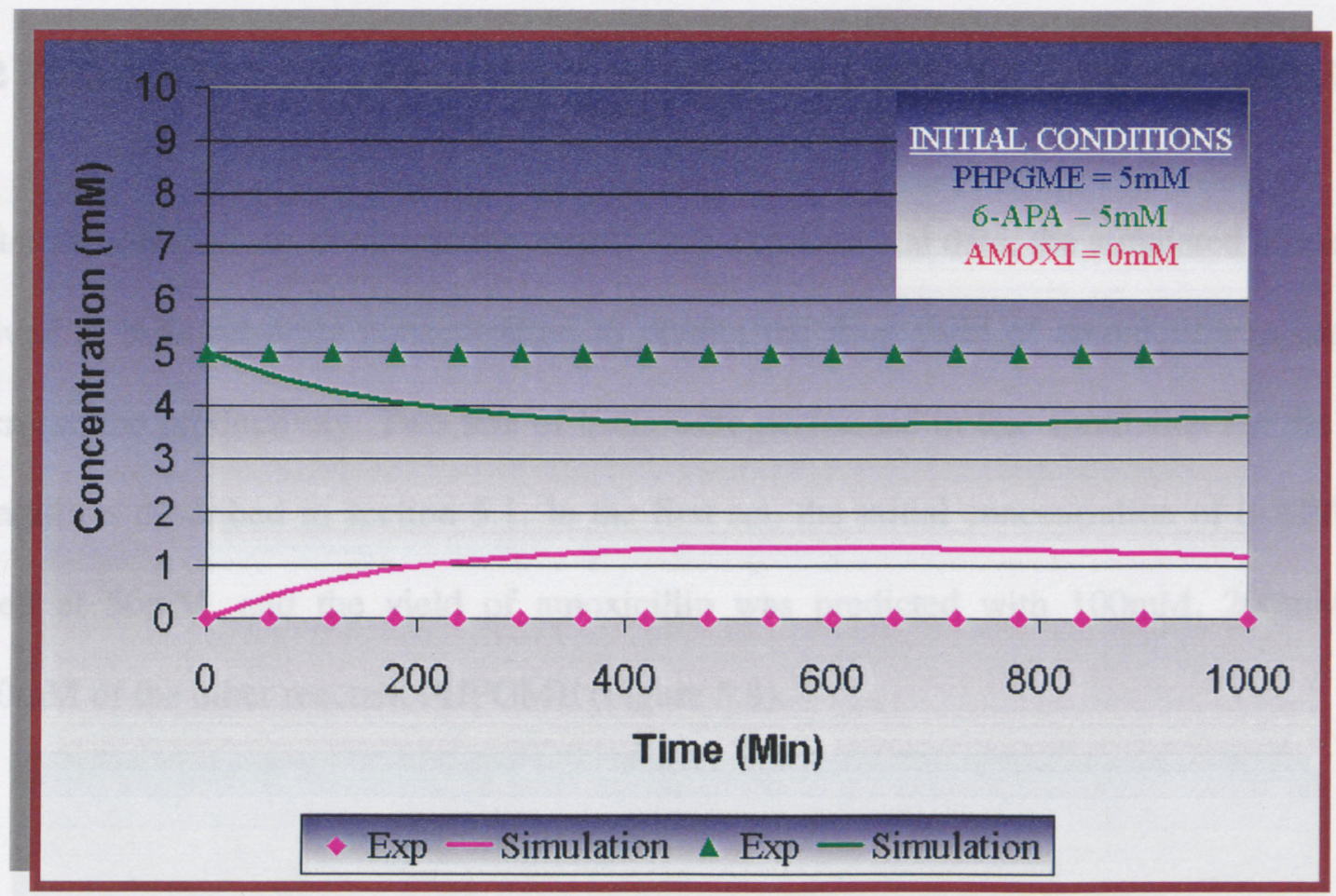

Figure 5.7 Comparison of simulation results with experimental data (Goncalves et al., 2002) at initial concentrations of 5mM 6-APA and 5mM PHPGME.

A general trend is shown on all the graphs shown above: although the Runga-Kutta simulation is not predicting individual experimental production of amoxicillin, it does relatively closely predict the maximum amoxicillin concentration at some point of the simulation. This gave enough confidence in the simulation to use it to predict the maximum yield of amoxicillin with high substrate and enzyme concentration. The next two sections 
will discuss the effect of high initial substrate and enzyme concentration during the production of amoxicillin.

\subsection{PREDICTION OF THE EFFECT OF HIGH SUBSTRATE CONCENTRATION}

After the comparison of simulation results with experimental data, the simulated model was solved at high substrate concentration to predict the final yield of amoxicillin in order to increase the productivity. Two sets of trials were performed in this simulation for the same conditions described in section 5.1. In the first set, the initial concentration of 6-APA was fixed at $50 \mathrm{mM}$, and the yield of amoxicillin was predicted with $100 \mathrm{mM}, 200 \mathrm{mM}$ and $300 \mathrm{mM}$ of the other reactant PHPGME (Figure 5.8).

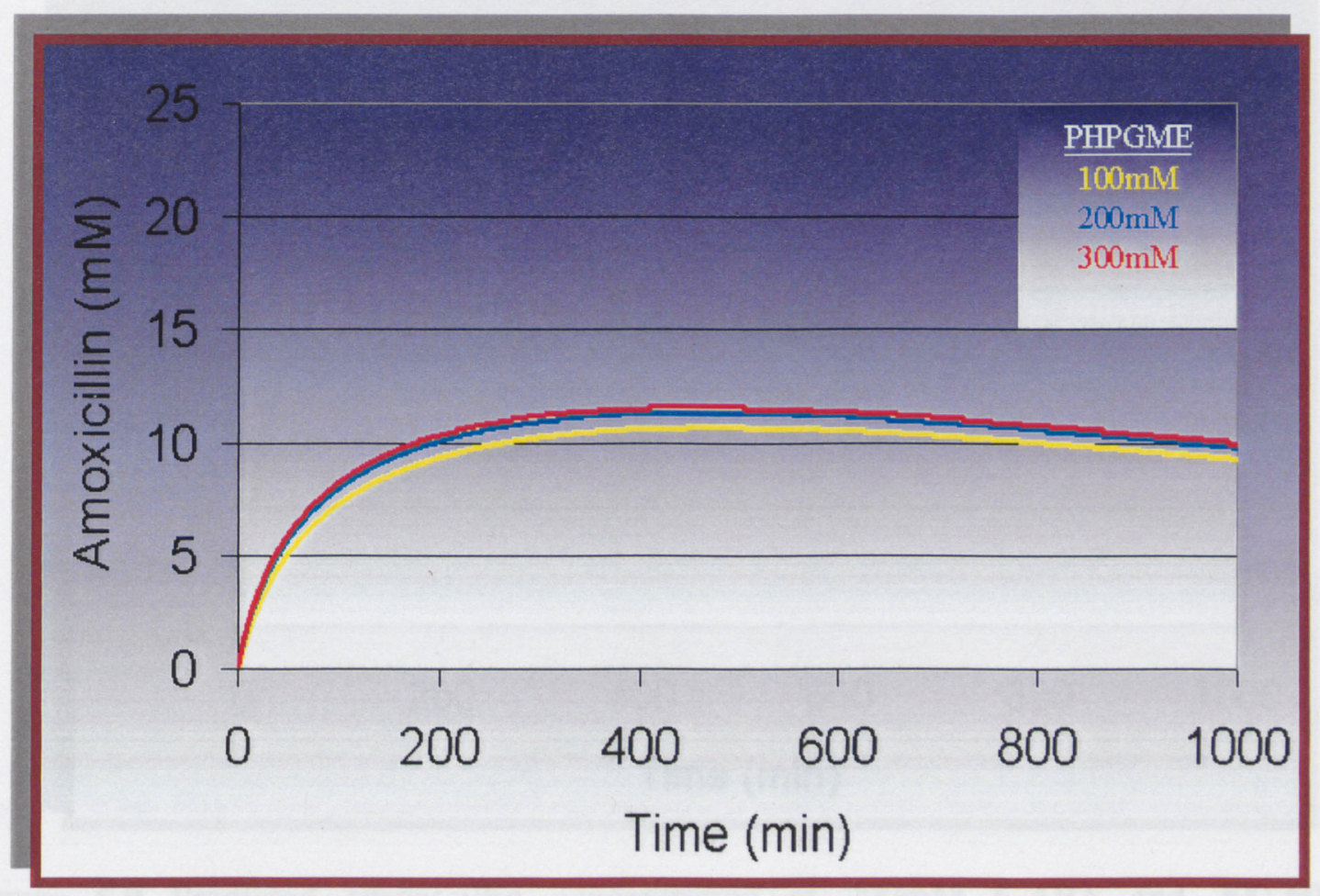

Figure 5.8 Predicted amoxicillin concentration at 50mM 6-APA and 100-300mM PHPGME. 
The simulation predicted a maximum concentration of $10.6 \mathrm{mM}$ of amoxicillin in 400 minutes when $100 \mathrm{mM}$ of PHPGME was used. This value increased to $11.4 \mathrm{mM}$ and $11.6 \mathrm{mM}$ with $200 \mathrm{mM}$ and $300 \mathrm{mM}$ of PHPGME, respectively. This showed that a higher concentration of PHPGME does not significantly increase the production of amoxicillin.

When the concentration of 6 -APA was fixed at $200 \mathrm{mM}$ and the range of concentration of PHPGME was doubled (Figure 5.9), a maximum concentration of $18.0-19.5 \mathrm{mM}$ of amoxicillin in 400 minutes was predicted. This was almost be twice the values obtained in Figure 5.8. At the higher end of PHPGME concentration, the effect of 6-APA seems to be diminishing, at least for the conditions used in this work.

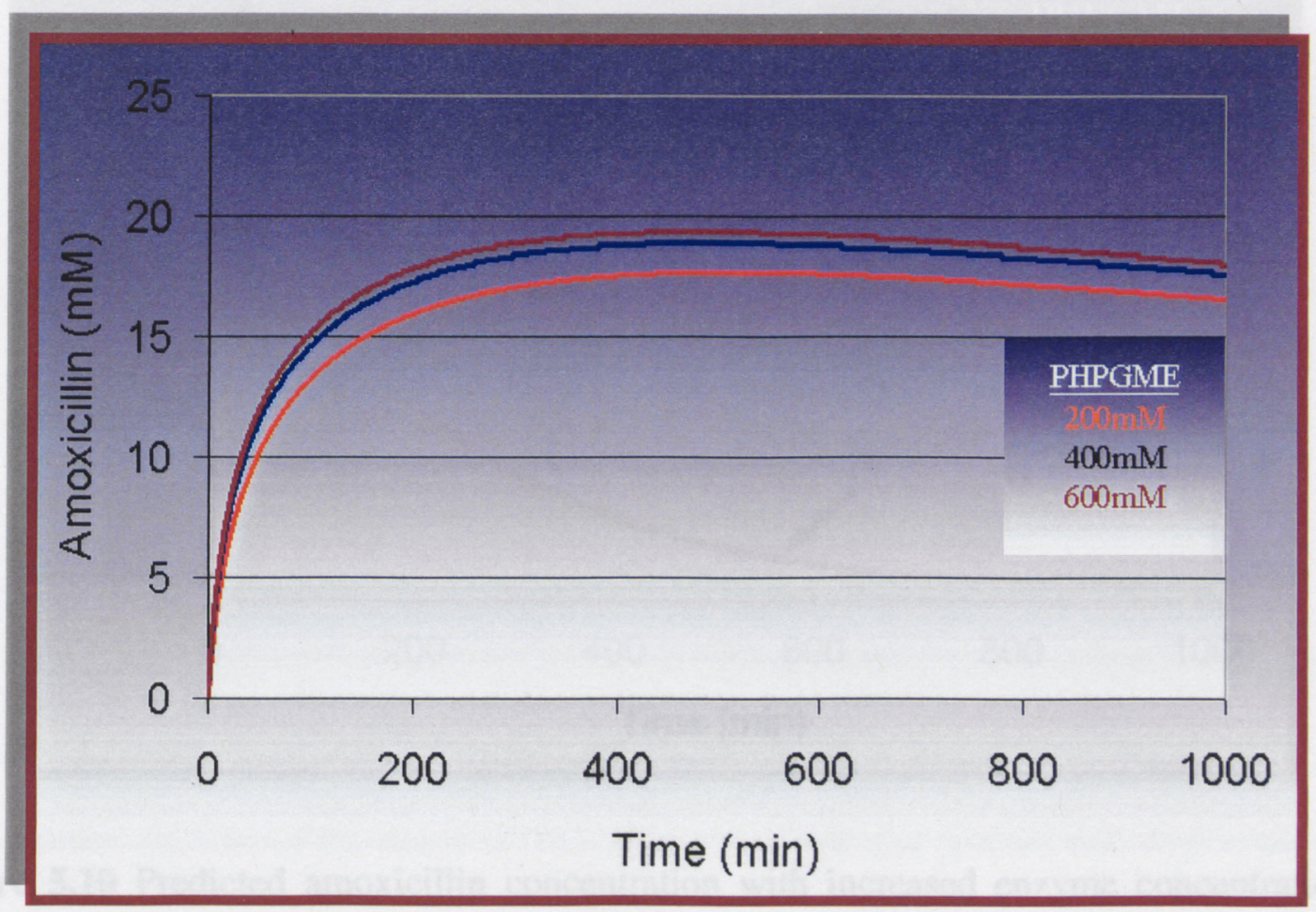

Figure 5.9 Predicted amoxicillin concentration at 200mM 6-APA and 200-600mM PHPGME. 


\subsection{PREDICTION OF THE EFFECT OF HIGH ENZYME CONCENTRATION}

The effect of high enzyme concentration was also studied for the enzymatic synthesis of amoxicillin in order to either increase the reaction rate or achieve a maximum yield in less time. The simulation runs were performed with four times more enzyme while other conditions remained the same to those of Figures 5.8 and 5.9. Increasing the amount of enzyme concentration with 50mM 6-APA (Figure 5.10) did not result in higher production of amoxicillin but its maximum concentration could be achieved in almost a quarter of the time faster than when $1 \mathrm{~g}$ of enzyme was used.

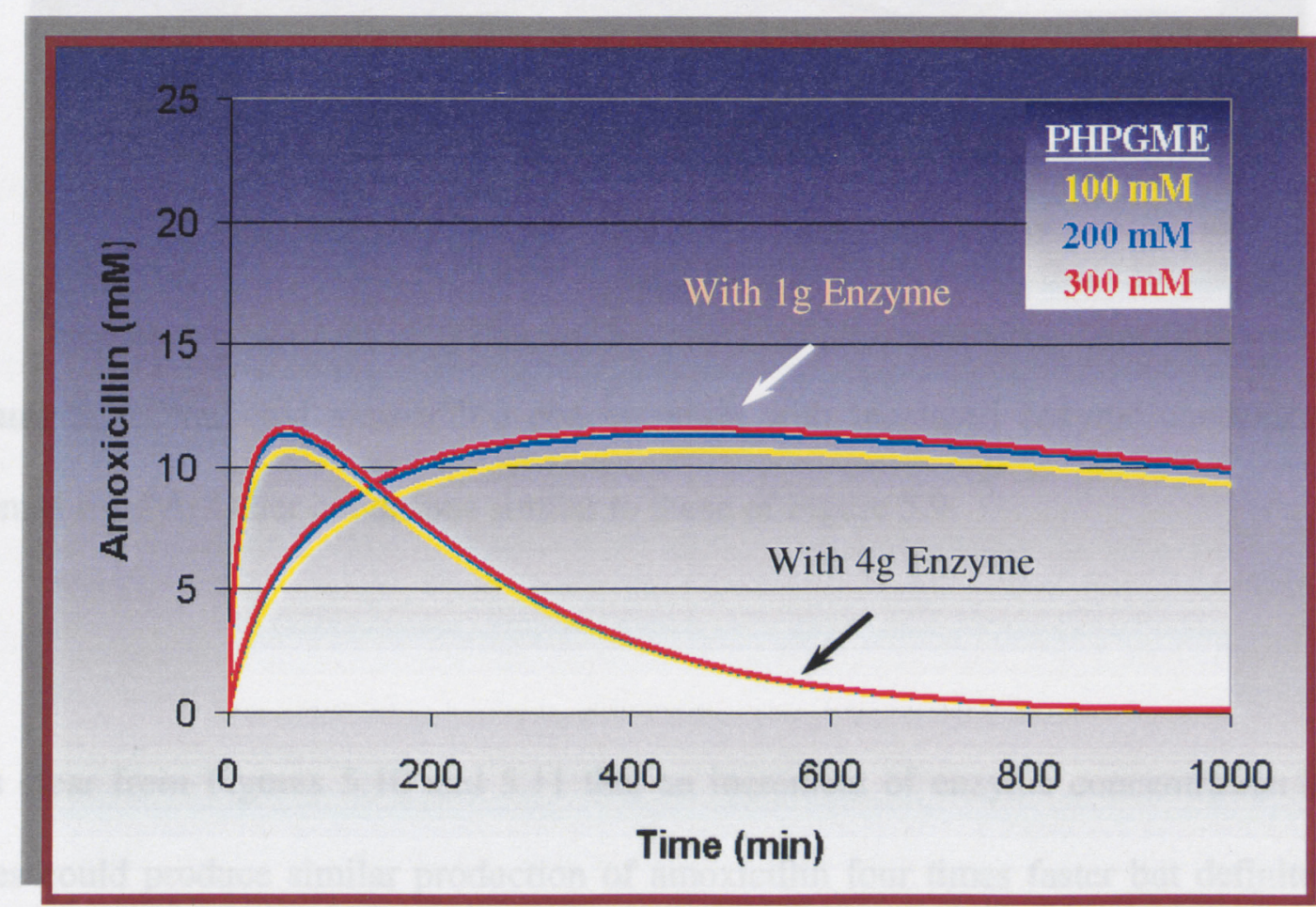

Figure 5.10 Predicted amoxicillin concentration with increased enzyme concentration at 50mM 6-APA. Other conditions similar to those of Figure 5.8. 
When the initial concentration of enzyme was quadrupled in the presence of four times more 6-APA and twice that of PHPGME than that reported in Figure 5.10, a similar trend in time reduction and in maximum amoxicillin concentration was observed.

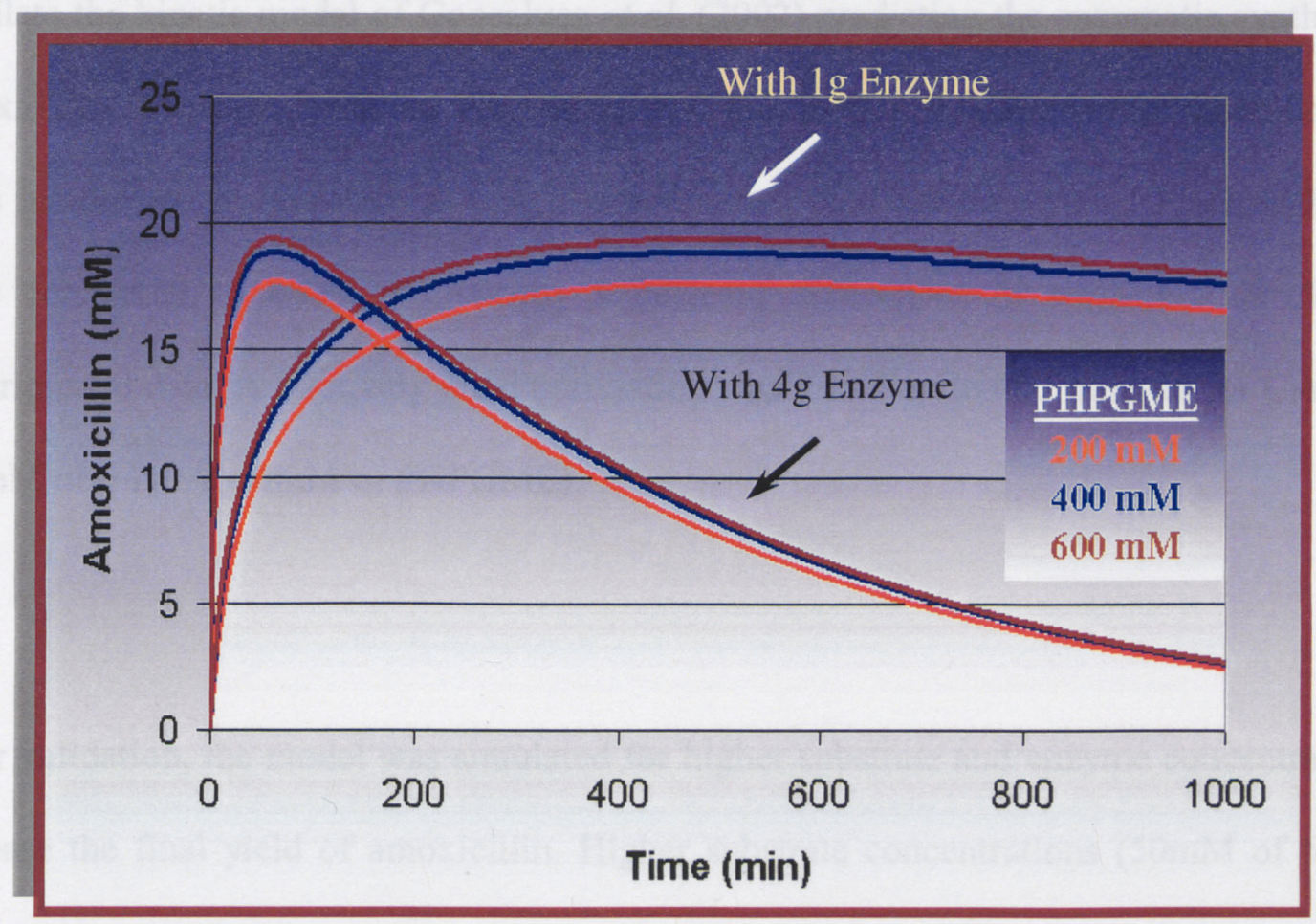

Figure 5.11 Predicted amoxicillin concentration with increased enzyme concentration at 200mM 6-APA. Other conditions similar to those of Figure 5.9.

It is clear from Figures 5.10 and 5.11 that an increment of enzyme concentration by four times could produce similar production of amoxicillin four times faster but definitely that will increase the cost of the reaction. The costs of enzyme and process will determine which option should be adopted on a commercial scale. 


\section{CHAPTER 6: CONCLUSION AND FUTURE WORK}

A C++ computer program was developed using a Fourth Order Runge-Kutta method to simulate the kinetic model of Goncalves et al. (2002) predicting the enzymatic synthesis of amoxicillin at various reactant concentrations. For model validation, the simulation was done for the same conditions at which experimental data were available. Fractional errors were calculated to assess statistically significant differences in simulation results and experimental data. A relatively good correlation was found up to 400 minutes for Case Two (50mM of 6-APA; 50mM of PHPGME).

After validation, the model was simulated for higher substrate and enzyme concentration to increase the final yield of amoxicillin. Higher substrate concentrations (50mM of 6-APA; $300 \mathrm{mM}$ of PHPGME) would result in a $24 \%$ yield of amoxicillin. Increasing the enzyme concentration by four times would produce similar amoxicillin yiélds, only four times faster. Also, a maximum of $40 \%$ amoxicillin yield of the initial concentration of 6-APA could be produced from this enzymatic process if the hydrolysis reactions could be suppressed.

For future work, it is recommended that experiments be performed at the high substrate and enzyme concentrations reported here so as to verify the simulation results obtained in this work. Some modifications are also required in the kinetic model to improve the correlation 
between simulation results and experimental data, or a new model could even be developed better predict this complex enzymatic reaction.

As discussed in the literature review, $\mathrm{pH}$ value plays a major role during the enzymatic synthesis of ampicillin. After studying the effect of $\mathrm{pH}$ from 5.5 to 8.0, Ospina et al. (1996) reported that up to $75 \%$ conversion of ampicillin could occur by controlling the $\mathrm{pH}$ at 6.0 . Since the chemical structure and the reaction kinetics of ampicillin are similar to those of amoxicillin, and the same enzyme is used for the synthesis of both antibiotics, it is recommended that the enzymatic synthesis reaction for amoxicillin be performed at $\mathrm{pH} 6.0$ (Figure 6.1).

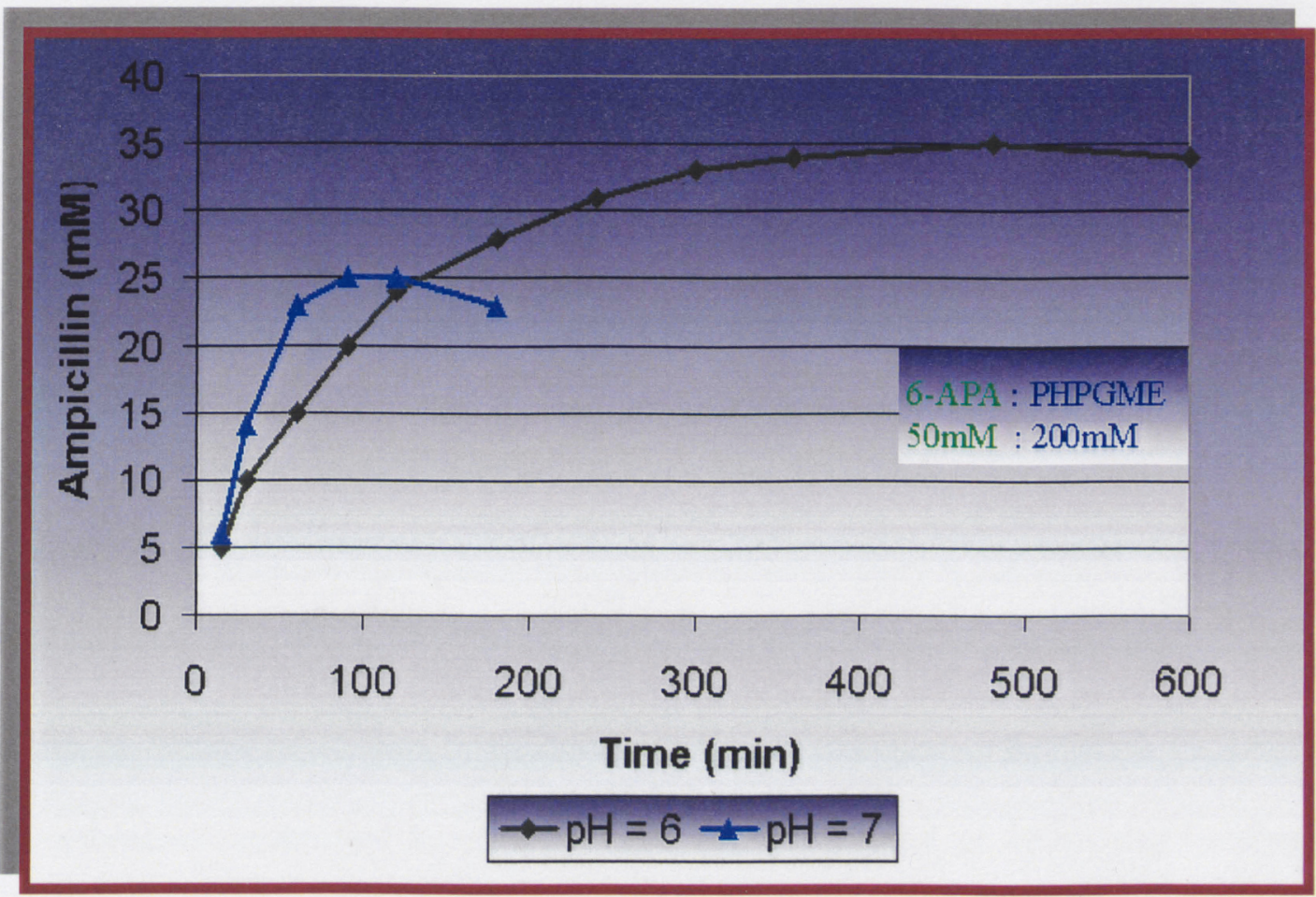

Figure 6.1 Ampicillin production at pH 6 and pH 7 (Ospina et al., 1996). 
It is clear from Figure 6.1 that more ampicillin can be obtained at $\mathrm{pH} 6$ than at $\mathrm{pH} 7$. However, it takes five times as long to get more than 1.5 times the maximum concentration reached at $\mathrm{pH} 7$ using the same amount of reactants and enzyme. Since simulation results with amoxicillin showed that similar antibiotic concentrations could be obtained in less time by increasing the enzyme concentration (Figures 5.10 and 5.11), faster increases in the maximum yield could be obtained by combining a lower $\mathrm{pH}(6.0$ instead of 6.5$)$ with more enzyme. 


\section{CHAPTER 7: REFERENCES}

Bailey J. E., and Ollis D. F. (1986). Biochemical Engineering Fundamentals, Second edition. New York, NY, McGraw-Hill Chemical Engineering Series.

Bickerstaff G. (1997). Immobilization of Enzymes and Cells. Methods in Biotechnology. Totowa, NJ, Humana Press.

Bock A., Wirth R., Schmid G., Shumacher G., Lan G., and Buckel P. (1983). The penicillin acylase from Escherichia coli ATCC 11105 consists of two dissimilar subunits. FEMS Microbiology Letters 20, 135-139.

Chapra S. C., and Canale R. P. (2002). Numerical Methods for Engineers with Software and Programming Applications, $4^{\text {th }}$ edition. New York, NY, McGraw-Hill Chemical Engineering Series.

. Clark D. S. (1994). Can immobilization be exploited to modify enzyme activity? TibTech $12,439-443$.

Diender M. B., Straathof A. J. J., Van D. W., Ras C., and Heijnen J. J. (1998). Feasibility of the thermodynamic controlled synthesis of amoxicillin. Journal of Molecular Catalysis A: Chemical 5, 249-53. 
Freeman A., and Lilly M. D. (1998). Effect of processing parameters on the feasibility and operational stability of immobilized viable microbial cells. Enzyme and Microbial Technology 23, 335-345.

Goncalves L. R. B., Fernandez L. R., Guisa'n J. M., and Giordano R. L. C. (2000). A kinetic study of the synthesis of amoxicillin using penicillin $\mathrm{G}$ acylase immobilized on agarose. Applied Biochemistry and Biotechnology 84-86, 931-945.

Goncalves L. R. B., Fernandez L. R., Guisa'n J. M., and Giordano R. L. C. (2002). The role of 6-aminopenicillanic acid on the kinetics of the enzymatic synthesis of amoxicillin catalyzed by penicillin g acylase immobilized on glyoxyl-agarose. Enzyme and Microbial Technology 131, 461-471.

Goncalves L. R. B., Fernandez L. R., Guisa'n J. M., Giordano R. C., and Giordano R. L. C. (2003). Inhibitory effects in the side reactions occurring during the enzymatic synthesis of amoxicillin p-hydroxyphenylglycine methyl ester and amoxicillin hydrolysis. Applied Biochemistry and Biotechnology $38,77-85$.

Guisan J. M. (1988). Aldehyde-agarose gels as activated supports for immobilizationstabilization of enzymes. Enzyme and Microbial Technology 10, 375-382. 
Halling P. J., Eichhorn U., Kuhl P., and Jakubke H. D. (1995). Thermodynamics of solid-tosolid conversion and application to enzymic peptide synthesis. Enzyme and Microbial Technology 17, 601-606.

Kaasgaard S. G., and Veitland U. (1996). Process for preparation of $\beta$-lactams utilizing a combined concentration of acylating agent plus $\beta$-lactam derivative of at least $400 \mathrm{~mm}$. US Patent No.5,525,483.

Kasche V. (1986). Mechanism and yields in enzyme catalyzed equilibrium and kinetically controlled synthesis of $\beta$-lactam antibiotics, peptides and other condensation products. Enzyme and Microbial Technology 8, 4-16.

Kheirolomoom A., Ardjmand M., Fazelinia H., and Zakeri A. (2001). Isolation of penicillin G acylase from Escherichia coli ATCC 11105 by physical and chemical treatments. Biochemical Engineering Journal 8, 223-227.

Kim M. G., and Lee S. B. (1996). Penicillin acylase-catalyzed synthesis of $\beta$-lactam antibiotics in water-methanol mixtures: effect of cosolvent content and chemical nature of substrate on reaction rates and yields. Journal of Molecular Catalysis B: Enzyme 1, 201-211.

Klibanov A. M. (1983). Stabilization of enzymes against thermal inactivation. Advances in Applied Microbiology 29, 1-28. 
Lafuente R. F., Rosell C. M., Alvaro G., and Guisan, J. M. (1992). Additional stabilization of penicillin $\mathrm{G}$ acylase-agarose derivatives by controlled chemical modification with formaldehyde. Enzyme and Microbial Technology 14, 489-495.

Martin L., Prieto M. A., Cortes E., and Garcia J. L. (1995). Cloning and sequencing of the pac gene encoding the penicillin G acylase of Bacillus megaterium ATCC 14945. FEMS Microbiology Letters 125, 287-292.

Ospina S., Barzana E., Ramirez O. T., and Munguia A. L. (1996). Effect of pH in the synthesis of ampicillin by penicillin acylase. Enzyme and Microbial Technology 19, 462469.

Rao S. S. (2002). Applied Numerical Methods for Engineers and Scientists. Englewood Cliffs, NJ, Prentice Hall.

Tewari Y. B, Schantz M. M, Pandey P. C, Rekharsky M. V, and Goldberg R. N. (1995). Thermodynamics of the hydrolysis of N-acetyl-L-phenylalanine ethyl ester in water and in organic solvents. Journal of Physical Chemistry 99, 1594-1601.

Vikartovska W., Michalkova A. E., and Gemeiner P. (1998). Enzyme flow microcalorimetry - a useful tool for screening of immobilized penicillin $G$ acylase. Journal of Chemical Technology and Biotechnology 73, 31-36. 


\section{APPENDIX A: FOURTH ORDER ALGORITHM FOR RUNGE-KUTTA METHOD}

The algorithm used for the Fourth Order Runge-Kutta method in this work is given by (Chapra and Canal, 2002):

$y[n]_{i+1}=y[n]_{i}+a h$

where: $\quad \mathrm{i}=$ iteration number

$\mathrm{n}=0,1$ and 2
$y[0]=\mathrm{C}_{\text {PHPGME }}$
$\mathrm{y}[1]=\mathrm{C}_{\mathrm{AMOXI}}$
$\mathrm{y}[2]=\mathrm{C}_{6-\mathrm{APA}}$

$a=\frac{1}{6}\left(k_{1}+2 k_{2}+2 k_{3}+k_{4}\right)$

$\mathrm{k}_{1}=\mathrm{f}\left(\mathrm{x}_{\mathrm{i}}, \mathrm{y}[\mathrm{n}]_{\mathrm{i}}\right)$

$k_{2}=f\left(x_{i}+\frac{1}{2} h, y[n]_{i}+\frac{1}{2} k_{1} h\right)$

$k_{3}=f\left(x_{i}+\frac{1}{2} h, y[n]_{i}+\frac{1}{2} k_{2} h\right)$

$k_{4}=f\left(x_{i}+h, y[n]_{i}+k_{3} h\right)$

$\mathrm{h}=0.1 \quad$ (Stepsize)

$\mathrm{x}_{\mathrm{i}}=$ Initial reaction time 


\section{APPENDIX B: C++ PROGRAM CODE}

\section{//File Amoxi.cpp}

\#include "de.h"

$\mathrm{DE}:: \mathrm{DE}(0\{/ /$ constructor

Input();

\}

$\mathrm{DE}:: \sim \mathrm{DE} 0\{/ /$ destructor

delete [] y, delete [] dydx, delete [] fileName;

\}

//INPUT VALUES

void DE::Input()\{//constructor

$\mathrm{n}=3 ; / / \#$ of DEs

$\mathrm{h}=.1 ; / /$ step size

$y=$ new double $[\mathrm{n}]$, dydx $=$ new double $[\mathrm{n}]$;

for(int $\mathrm{i}=0 ; \mathrm{i}<3 ; \mathrm{i}++)$ y $[\mathrm{i}]=0 ; / /$ initial condition

$y[0]=70 ;$

$y[1]=0$;

$y[2]=100 ;$

$/ / y[0]=C P H P G M E$ (Concentration of PHPGME)

$/ / y[1]=$ CAMOXI (Concentration of amoxicillin)

$/ / y[2]=$ C6APA (Concentration of 6-APA)

$x i=0 ; x f=1000 ; / /($ time range) 
fileName=new char [20];

strcpy(fileName,"out.txt"); //(output file name)

\}

void DE::derivs(double $\mathrm{x}$,double *y,double *dy)

\{

$/ /$ kcat $1=$ (Rate constant to PHPGME hydrolysis)

$/ / \mathrm{kcat} 2=($ Rate constant to amoxicillin hydrolysis $)$

$/ / \mathrm{Km} 1=$ (Michaelis-Menten constant for PHPGME hydrolysis)

$/ / \mathrm{Km} 2=($ Michaelis-Menten constant for amoxicillin hydrolysis $)$

//kAMOXI= (kinetic rate constant for amoxicillin)

$/ / \mathrm{kPHPGME}=($ kinetic rate constant for PHPGME)

$/ / \mathrm{kPHPG}=($ kinetic rate constant for $\mathrm{p}$-hydroxyphenylglycine)

$/ / \mathrm{k} 6 \mathrm{APA}=($ kinetic rate constant for 6 -aminopenicillanic acid)

$/ / \mathrm{KENZYME}=($ Nucleus adsorption constant $)$

$/ / C E N Z Y M E=($ Concentration of enzyme $)$

$/ / \mathrm{CPHPG}=($ Concentration of $\mathrm{p}$-hydroxyphenylglycine $)$

$/ / \mathrm{pH}=6.5$ and Temperature $=25$ Degree $\mathrm{C}$

double kcat $1=0.18, \mathrm{kcat} 2=0.33$;

double $\mathrm{Km} 1=7.905, \mathrm{Km} 2=12.509$;

double

kPHPGME=3.78,kAMOXI=9.174,kPHPG=10.907,k6APA=62.044,KENZYME=14.350;

double $R \max =0.606$;

double CENZYME=.1; 
double $\mathrm{CPHPG}=0$;

double VAMOXI, VPHPGME, VSYNTHESIS, X;

$\mathrm{X}=\mathrm{y}[2] / \mathrm{KENZYME}+\mathrm{y}[2]$

//Rate of amoxicillin hydrolysis (VAMOXI)

VAMOXI $=\mathrm{kcat} 2 * \mathrm{y}[1] * \mathrm{CENZYME} /(\mathrm{Km} 2 *(1+(\mathrm{y}[0] / \mathrm{kPHPGME})+(\mathrm{y}[2] / \mathrm{k} 6 \mathrm{APA})+(\mathrm{CPHPG} / \mathrm{k}$ PHPG))+y[1]);

//Rate of PHPGME hydrolysis (VPHPGME)

VPHPGME=kcat $1 * \mathrm{y}[0] *$ CENZYME/Km $1 *(1+\mathrm{y}[1] / \mathrm{kAMOXI}+(\mathrm{CPHPG} / \mathrm{kPHPG})+\mathrm{y}[0])$;

//rate of amoxicillin synthesis (VSYNTHESIS)

VSYNTHESIS $=\mathrm{kcat} 1 * \mathrm{y}[0] * \mathrm{CENZYME} * \mathrm{Rmax} * \mathrm{X} /(\mathrm{Km} 1 *(1+\mathrm{y}[2] / \mathrm{kAMOXI}+\mathrm{CPHPG} / \mathrm{kPHP}$ $\mathrm{G})+\mathrm{y}[0])$

//Equations for mass balance

dy[0]=-VPHPGME;

dy[1]=VSYNTHESIS-VAMOXI;

dy[2]=VAMOXI-VSYNTHESIS;

\}

//BASIC OUTPUT

void DE::Print(ostream \&stream)\{ 


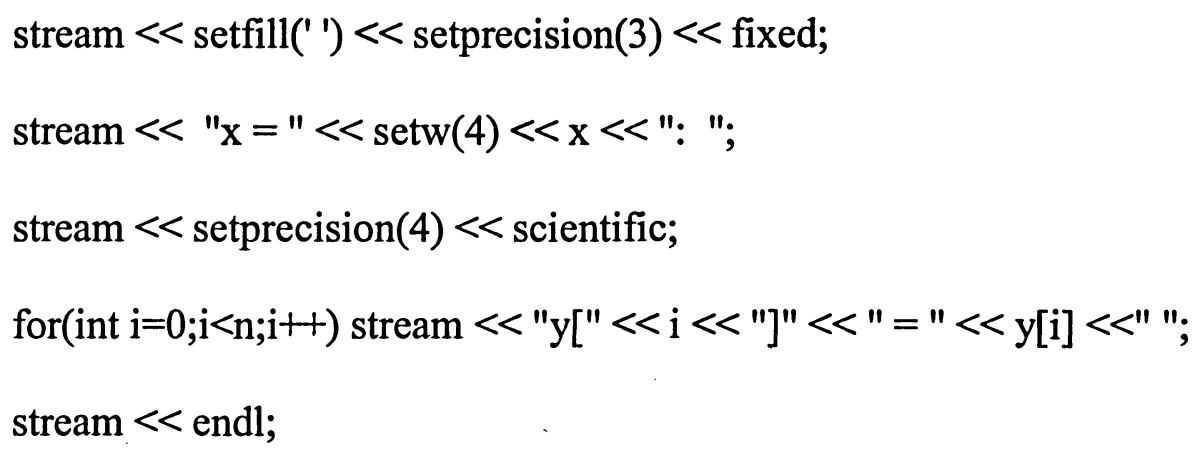

\section{//File main.cpp}

\#include "rk4.h"

int main 0\{

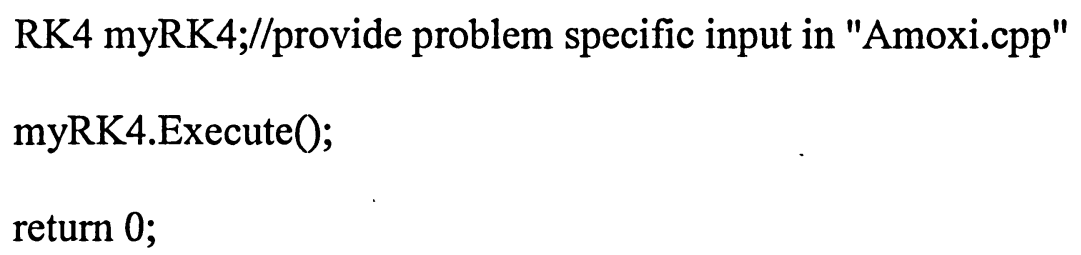

\section{//File rk4.cpp}

\#include "rk4.h"

RK4::RK40:DE()

dym=new double $[\mathrm{n}]$, dyt=new double $[\mathrm{n}], \mathrm{yt}=$ new double $[\mathrm{n}]$;

\}

RK4:: RK40\{ 
delete [] dym, delete [] dyt, delete [] yt;

\}

void RK4::Execute()\{

ofstream out(fileName);

$\mathrm{x}=\mathrm{xi}$;

Print(cout);Print(out);

for $(; x<=x f ; x+=h)\{$

derivs(x,y,dydx);

RKStep(;

Print(cout);Print(out);

\}

out.close();

\}

void RK4::RKStep() \{//does one integration step

int $\mathrm{i}$;

double xh,hh,h6;

$\mathrm{hh}=\mathrm{h}^{*} 0.5$

$\mathrm{h} 6=\mathrm{h} / 6.0$

$\mathrm{xh}=\mathrm{x}+\mathrm{hh}$;

for $(i=0 ; i<n ; i++) y t[i]=y[i]+h h^{*} d y d x[i]$;

derivs(xh,yt,dyt);

for $(i=0 ; i<n ; i++)$ yt $[i]=y[i]+h h^{*} \operatorname{dyt}[i]$;

derivs(xh,yt,dym); 


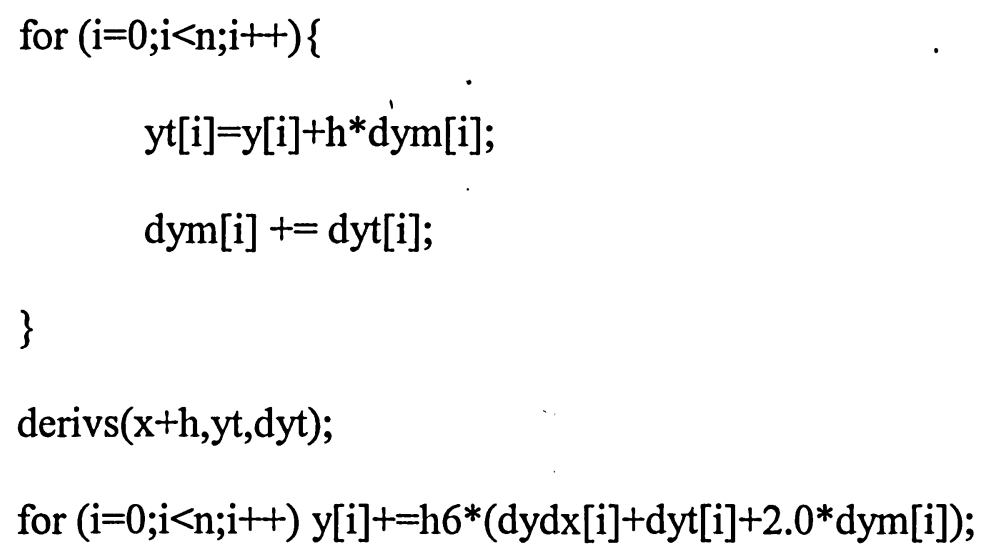

\}

//File de.h

\#ifndef_DE_h

\#define_DE_h

\#include "util.h"

//base class to solve differential equations

class $\mathrm{DE}\{$

protected:

char *fileName;

double $x, x i, x f, h,{ }^{*} y,{ }^{*} d y d x ;$

int $\mathrm{n}$;

void Input(),derivs(double $\mathrm{x}$, double *y, double *dy);

public:

DE();

$\sim \mathrm{DE}$; 
virtual void Print(ostream \&stream);//may be overridden virtual void Execute $(\{\} ; / /$ to be overidden

\};

\#endif

\section{//File rk4.h}

\#ifndef_RK4_h

\#define_RK4_h

\#include "de.h"

//Runge-Kutta 4th order

class RK4:public DE\{

void RKStep(;//does one integration step

double ${ }^{*}$ dym, ${ }^{*}$ dyt, ${ }^{*}$ yt;

public:

RK4();//constructor

$\sim$ RK4();//destructor

void Execute();

\};

\#endif

//File util.h

\#ifndef_UTIL_H 
\#define_UTIL_H

\#include <string $>$

\#include $<$ cmath $>$

\#include <complex $>$

\#include <iostream>

\#include $<$ fstream $>$

\#include $<$ iomanip $>$

using namespace std;

template $<$ class $\mathrm{T}>$

inline const $\mathrm{T}$ SQR(const $\mathrm{T}$ a) \{return $\mathrm{a}^{*} \mathrm{a}$; $\}$

template $<$ class $\mathrm{T}>$

inline const $\mathrm{T}$ MAX(const $\mathrm{T} \& \mathrm{a}$, const $\mathrm{T} \& \mathrm{~b}$ )

$$
\text { \{return } \mathrm{b}>\mathrm{a} \text { ? (b) : (a); }
$$

inline float MAX(const double \&a, const float $\& b$ )

$$
\text { \{return } b>a \text { ? (b) : float(a); }
$$

inline float MAX(const float \&a, const double \&b)

$$
\text { \{return } b>a \text { ? float(b) : (a); }
$$

template $<$ class $\mathrm{T}>$

inline const $\mathrm{T}$ MIN(const $\mathrm{T} \& \mathrm{a}$, const $\mathrm{T} \& \mathrm{~b}$ )

$$
\{\text { return } \mathrm{b}<\mathrm{a} \text { ? (b) : (a); }
$$

inline float MIN(const double \&a, const float \&b)

$$
\{\text { return } b<a ? \text { ? (b) : float(a); }
$$


inline float MIN(const float \&a, const double \&b)

$$
\text { \{return } \mathrm{b}<\mathrm{a} \text { ? float(b) : (a); }
$$

template $<$ class $\mathrm{T}>$

inline const T SIGN(const T \&a, const T \&b)

$$
\{\text { return } \mathrm{b}>=0 \text { ? }(\mathrm{a}>=0 \text { ? } \mathrm{a}:-\mathrm{a}):(\mathrm{a}>=0 \text { ? }-\mathrm{a}: \mathrm{a}) ;\}
$$

inline float SIGN(const float \&a, const double \&b)

$$
\{\text { return } \mathrm{b}>=0 \text { ? }(\mathrm{a}>=0 \text { ? } \mathrm{a}:-\mathrm{a}):(\mathrm{a}>=0 \text { ? }-\mathrm{a}: \mathrm{a}) ;\}
$$

inline float SIGN(const double \&a, const float \&b)

$$
\{\text { return } b>=0 ?(a>=0 ? a:-a):(a>=0 ?-a: a) ;\}
$$

template $<$ class $\mathrm{T}>$

inline void SWAP(T \&a, T \&b)

$$
\{\mathrm{T} \text { dum=a; } \mathrm{a}=\mathrm{b} ; \mathrm{b}=\mathrm{dum} ;\}
$$

\#endif 


\section{APPENDIX C: EXPERIMENTAL DATA FROM LITERATURE}

Experimental data were extracted from graphs (Goncalves et al., 2000; 2002; 2003).

Table C.1 Experimental data for the enzymatic synthesis of amoxicillin at pH 6.5 and $25^{\circ} \mathrm{C}$ with $100 \mathrm{mM}$ of $6-A P A$ reacting with $70 \mathrm{mM}$ of PHPGME in the presence of $1 \mathrm{~g}$ of $30 \mathrm{IU} / \mathrm{ml}$ PGA.

\begin{tabular}{|c|c|c|}
\hline $\begin{array}{c}\text { Time } \\
(\text { Min })\end{array}$ & $\begin{array}{c}\text { Concentration of AMOXI } \\
(\mathbf{m M})\end{array}$ & $\begin{array}{c}\text { Concentration of 6-APA } \\
(\mathbf{m M})\end{array}$ \\
\hline 0 & 0 & 100 \\
\hline 60 & 05.0 & 95 \\
\hline 120 & 10.0 & 87 \\
\hline 180 & 12.5 & 84 \\
\hline 240 & 14.8 & 84 \\
\hline 300 & 15.9 & 84 \\
\hline 360 & 17.0 & 84 \\
\hline 420 & 17.0 & 84 \\
\hline 480 & 16.0 & 85 \\
\hline 540 & 15.0 & 84 \\
\hline 600 & 14.0 & \\
\hline
\end{tabular}


Table C.2 Experimental data for the enzymatic synthesis of amoxicillin at $\mathrm{pH} 6.5$ and $25^{\circ} \mathrm{C}$ with $50 \mathrm{mM}$ of $6-\mathrm{APA}$ reacting with $50 \mathrm{mM}$ of PHPGME in the presence of $1 \mathrm{~g}$ of $30 \mathrm{IU} / \mathrm{ml}$ PGA.

\begin{tabular}{|c|c|c|}
\hline $\begin{array}{c}\text { Time } \\
(\text { Min) }\end{array}$ & $\begin{array}{c}\text { Concentration of AMOXI } \\
(\mathbf{m M})\end{array}$ & $\begin{array}{c}\text { Concentration of 6-APA } \\
(\mathbf{m M})\end{array}$ \\
\hline 0 & 0 & 50 \\
\hline 60 & 5.0 & 42 \\
\hline 120 & 7.0 & 41 \\
\hline 180 & 8.3 & 40 \\
\hline 240 & 9.4 & 40 \\
\hline 300 & 10 & 41 \\
\hline 360 & 10 & 42 \\
\hline 420 & 9.0 & 42.5 \\
\hline 480 & 8.0 & 43 \\
\hline 540 & 6.7 & \\
\hline 600 & 5.0 & 41 \\
\hline & & \\
\hline
\end{tabular}


Table C.3 Experimental data for the enzymatic synthesis of amoxicillin at $\mathrm{pH} 6.5$ and $25^{\circ} \mathrm{C}$ with $5 \mathrm{mM}$ of $6-\mathrm{APA}$ reacting with $80 \mathrm{mM}$ of PHPGME in the presence of $1 \mathrm{~g}$ of $30 \mathrm{IU} / \mathrm{ml}$ PGA.

\begin{tabular}{|c|c|c|}
\hline $\begin{array}{c}\text { Time } \\
(\text { Min })\end{array}$ & $\begin{array}{c}\text { Concentration of AMOXI } \\
(\mathbf{m M})\end{array}$ & $\begin{array}{c}\text { Concentration of 6-APA } \\
(\mathbf{m M})\end{array}$ \\
\hline 0 & 0 & 5.5 \\
\hline 5 & 0.4 & 4.2 \\
\hline 10 & 0.64 & 4.0 \\
\hline 15 & 0.9 & 3.8 \\
\hline 20 & 1.2 & 3.6 \\
\hline 25 & 1.4 & 2.9 \\
\hline 60 & 2 & 3.1 \\
\hline 125 & 2 & 3.2 \\
\hline 175 & 1.9 & \\
\hline 240 & 1.5 & \\
\hline
\end{tabular}


Table C.4 Experimental data for the enzymatic synthesis of amoxicillin at pH 6.5 and $25^{\circ} \mathrm{C}$ with $5 \mathrm{mM}$ of $6-\mathrm{APA}$ reacting with $5 \mathrm{mM}$ of PHPGME in the presence of $1 \mathrm{~g}$ of $30 \mathrm{IU} / \mathrm{ml}$ PGA.

\begin{tabular}{|c|c|c|}
\hline $\begin{array}{c}\text { Time } \\
(\text { Min) }\end{array}$ & $\begin{array}{c}\text { Concentration of AMOXI } \\
(\mathbf{m M})\end{array}$ & $\begin{array}{c}\text { Concentration of 6-APA } \\
(\mathrm{mM})\end{array}$ \\
\hline 0 & 0 & 5 \\
\hline 60 & 0 & 5 \\
\hline 120 & 0 & 5 \\
\hline 180 & 0 & 5 \\
\hline 240 & 0 & 5 \\
\hline 300 & 0 & 5 \\
\hline 360 & 0 & 5 \\
\hline 420 & 0 & 5 \\
\hline 480 & 0 & 5 \\
\hline 540 & 0 & 5 \\
\hline 600 & 0 & 5 \\
\hline
\end{tabular}

